\title{
Metal-Promoted Aromatic Ring Amination and Deamination Reactions at a Diazo Ligand Coordinated to Rhodium and Ruthenium
}

\author{
Chayan Das, ${ }^{\dagger}$ Amit K. Ghosh, ${ }^{\dagger}$ Chen-Hsiung Hung, ${ }^{\ddagger}$ Gene-Hsiang Lee,,${ }^{\S}$ Shie-Ming Peng,,${ }^{\S}$ and \\ Sreebrata Goswami ${ }^{*}, \dagger$ \\ Department of Inorganic Chemistry, Indian Association for the Cultivation of Science, \\ Kolkata 700 032, India, Department of Chemistry, National Changhua University of Education, \\ Changhua, Taiwan 500, Republic of China, and Department of Chemistry, National Taiwan \\ University, Taipei, Taiwan, Republic of China
}

Received June 24, 2002

\begin{abstract}
Reactions of $\mathrm{MCl}_{3} \cdot 3 \mathrm{H}_{2} \mathrm{O}\left(\mathrm{M}=\mathrm{Rh}\right.$ and $\mathrm{Ru}$ ) with the ligand 2-[(2-N-arylamino)phenylazo]pyridine $\left[\mathrm{HL}^{1} ; \mathrm{NH}_{4} \mathrm{C}_{5} \mathrm{~N}=\right.$ $\mathrm{NC}_{6} \mathrm{H}_{4} \mathrm{~N}(\mathrm{H}) \mathrm{C}_{6} \mathrm{H}_{4}(\mathrm{H})\left(\mathrm{HL}^{1 \mathrm{a}}\right), \mathrm{NH}_{4} \mathrm{C}_{5} \mathrm{~N}=\mathrm{NC}_{6} \mathrm{H}_{4} \mathrm{~N}(\mathrm{H}) \mathrm{C}_{6} \mathrm{H}_{4}\left(\mathrm{CH}_{3}\right)\left(\mathrm{HL}^{1 \mathrm{~b}}\right)$, and $\left.\mathrm{NH}_{4} \mathrm{C}_{5} \mathrm{~N}=\mathrm{NC}_{6} \mathrm{H}_{4} \mathrm{~N}(\mathrm{H}) \mathrm{C}_{5} \mathrm{H}_{4} \mathrm{~N}\left(\mathrm{HL}^{1 \mathrm{c}}\right)\right]$ in the presence of dilute $\mathrm{NEt}_{3}$ afforded multiple products. In the case of rhodium, two green compounds, viz. $\left[R h\left(L^{1}\right)_{2}\right]^{+}$ $\left([2]^{+}\right)$and $\left[\mathrm{RhCl}(\text { pap })\left(\mathrm{L}^{1}\right)\right]^{+}\left([3]^{+}\right)$, where $\mathrm{L}^{1}$ and pap stand for the conjugate base of $\left[\mathrm{HL}^{1}\right]$ and 2-(phenylazo)pyridine, respectively, were separated on a preparative thin layer chromatographic plate. The reaction of $\mathrm{RuCl}_{3}$. $3 \mathrm{H}_{2} \mathrm{O}$, on the other hand, produced two brown compounds, viz. $\left[\mathrm{RuCl}\left(\mathrm{HL}^{1}\right)\left(\mathrm{L}^{1}\right)\right](4)$ and $\left[\mathrm{RuCl}(\mathrm{pap})\left(\mathrm{L}^{1}\right)\right](5)$, respectively, as the major products. The X-ray structures of the representative complexes are reported. Except for complex 2, and 4 , the products are formed due to the cleavage of an otherwise unreactive $\mathrm{C}$ (phenyl) $-\mathrm{N}($ amino) bond. In complex 4 , one of the tridentate ligands $\left(\mathrm{HL}^{1}\right)$ does not use its maximum denticity and coordinates as a neutral bidentate donor. Plausible reasons for the differences in their modes of coordination of the ligands as in $\mathbf{2}$ and $\mathbf{4}$ have been discussed. The ligand pap in the cationic mixed ligand complex [3]+ reacts instantaneously with $\mathrm{ArNH}_{2}$ to produce an ink-blue compound, $\left[\mathrm{RhCl}\left(\mathrm{HL}^{2}\right)\left(\mathrm{L}^{1}\right)\right]^{+}\left([6]^{+}\right)$in a high yield. The ligand $\mathrm{HL}^{2}$ is formed due to regioselective fusion of $\mathrm{ArNH}_{2}$ residue at the para carbon of the phenyl ring (with respect to the azo fragment) of pap in [3] $]^{+}$. The above complexes are generally intensely colored and show strong absorptions in the visible region, which are assigned to intraligand charge transfer transitions. These complexes undergo multiple and successive one-electrontransfer processes at the cathodic potentials. Electrogenerated cationic complexes of ruthenium(III), $[4]^{+}$and $[5]^{+}$, showed rhombic EPR spectra at $77 \mathrm{~K}$.
\end{abstract}

\section{Introduction}

The chemical reactions that are associated ${ }^{1}$ with bondmaking and bond-breaking processes in organic molecules have been of immense interest. In this respect, the reactions of coordinated ligands are important. ${ }^{2}$ In fact, these provide facile synthetic routes for the synthesis of many novel

* Author to whom correspondence should be addressed. Fax: (+91) 33473 2805. E-mail: icsg@mahendra.iacs.res.in.

$\dagger$ Indian Association for the Cultivation of Science.

$\div$ National Changhua University of Education.

$\S$ National Taiwan University.

(1) See, for example: (a) Hartwig, J. F. Acc. Chem. Res. 1998, 31, 852. (b) Lockwood, M. A.; Fanwick, P. E.; Einentein, O.; Rothwell, I. P. J. Am. Chem. Soc. 1996, 118, 2762. (c) Lahiri, G. K.; Goswami, S.; Falvello, L. R.; Chakravorty, A. Inorg. Chem. 1987, 26, 3365. (d) Li, Z.; Quan, R. W.; Jacobsen, E. N. J. Am. Chem. Soc. 1995, 117, 5889. (e) Kuwabe, S.; Torraca, K. E.; Buchwald, S. L. J. Am. Chem. Soc. 2001, 123, 12202 .

10.1021/ic020421c CCC: $\$ 22.00$ @ 2002 American Chemical Society Published on Web 11/23/2002 molecules, which are otherwise difficult, or in some cases even impossible, to synthesize following conventional synthetic procedures. In the recent years we have noted a number of metal-promoted $\mathrm{C}-\mathrm{N}$ bond forming processes ${ }^{3-12}$ includ-

(2) Selected leading references: (a) Hegedus, L. S. Coord. Chem. Rev. 1997, 161, 129. (b) Hegedus, L. S. Coord. Chem. Rev. 1998, 168, 49. (c) Hegedus, L. S. Coord. Chem. Rev. 1998, 175, 159. (d) Naota, T.; Takaya, H.; Murahashi, S.-I. Chem. Rev. 1998, 98, 2599. (e) Black, D. St. C. Comprehensive Coordination Chemistry; Wilkinson, G., Ed.; Pergamon: Oxford, 1987; Vol. 1, p 415. (f) Black, D. St. C. Comprehensive Coordination Chemistry; Wilkinson, G., Ed.; Pergamon: Oxford, 1987; Vol. 6, p 155. (g) Kondo, T.; Okada, T.; Mitsudo, T. J. Am. Chem. Soc. 2002, 124, 186.

(3) Mitra, K. N.; Goswami, S. Inorg. Chem. 1997, 36, 1322.

(4) Mitra, K. N.; Majumdar, P.; Peng, S.-M.; Castiñeiras, A.; Goswami, S. Chem. Commun. 1997, 1267.

(5) Mitra, K. N.; Peng, S.-M.; Goswami, S. Chem. Commun. 1998, 1685.

(6) Mitra, K. N.; Choudhury, S.; Castiñeiras, A.; Goswami, S. J. Chem. Soc., Dalton Trans. 1998, 2901.

Inorganic Chemistry, Vol. 41, No. 26, 2002 
Das et al.

Scheme 1

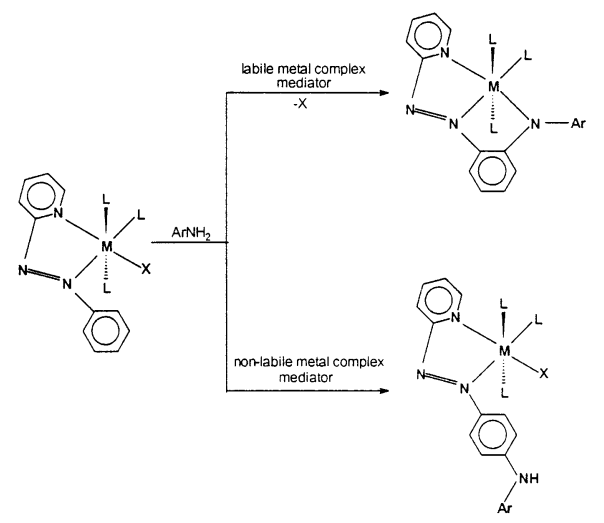

ing the fusion of aromatic amines at a coordinated diazo ligand, 2-(phenylazo)pyridine (pap). We note here that amination of an aromatic ring that occurs with $\mathrm{C}-\mathrm{N}$ bond formation is difficult but is a synthetically useful reaction.

In the course of our investigations on the amination of pap ligands in $\mathrm{M}$-pap complexes, we were concerned with the site selectivity of the fusion of $\mathrm{ArNH}_{2}$ at the pendant phenyl ring of the coordinated diazo ligand (Scheme 1). We recently have noted ${ }^{9}$ that one of the two pap ligands in the rhodium complex $\left[\mathrm{RhCl}_{2}(\text { pap })_{2}\right]^{+}\left([\mathbf{1}]^{+}\right)$undergoes amination at the ortho carbon to result in a tridentate ligand, while the second pap ligand in the above rhodium complex is aminated at the para carbon and thus produces a bidentate ligand. These results have prompted us to look further into the above fusion reactions. To understand the reasons for the site selection of the above amination reaction, we have designed and carried out the chemical reactions starting from some chosen rhodium substrates. In this context, we found it worthwhile to compare the results with the ruthenium analogues. Bivalent ruthenium is isoelectronic with trivalent rhodium; however, the properties of these two are vastly different, which has been useful for understanding the above fusion reactions of coordinated pap ligands.

The primary aim of this paper is to look into the aromatic amine fusion reactions of metal-coordinated pap ligand. These have been followed by the isolation of the intermediates as well as the final products. In all cases, identifications of the products are made, beyond doubt, by use of singlecrystal X-ray structure analysis.

\section{Results and Discussion}

Reaction of Preformed $\mathrm{HL}^{\mathbf{1}}$ and $\mathrm{RhCl}_{3} \cdot 3 \mathrm{H}_{2} \mathrm{O}$. We first consider the products obtained from the reaction of the preformed tridentate ligand $\mathrm{HL}^{1}$ with hydrated $\mathrm{RhCl}_{3}$. The

(7) Ghosh, A. K.; Mitra, K. N.; Mostafa, G.; Goswami, S. Eur. J. Inorg. Chem. 2000, 1961

(8) Majumdar, P.; Falvello, L. R.; Tomas, M.; Goswami, S. Chem. Eur. J. 2001, 7, 5222 .

(9) Saha, A.; Ghosh, A. K.; Majumdar, P.; Mitra, K. N.; Mondal, S.; Rajak, K. K.; Falvello, L. R.; Goswami, S. Organometallics 1999, 18, 3372.

(10) Ghosh, A. K.; Majumdar, P.; Falvello, L. R.; Mostafa, G.; Goswami, S. Organometallics 1999, 18, 5086.

(11) Saha, A.; Majumdar, P.; Peng, S.-M.; Goswami, S. Eur. J. Inorg. Chem. 2000, 2631.

(12) (a) Wolfe, J. P.; Wagaw, S.; Marcoux, J.-F.; Buchwald, S. L. Acc. Chem. Res. 1998, 31, 805. (b) Hartwig, J. F. Angew. Chem., Int. Ed. 1998, 37, 2046.
Scheme 2

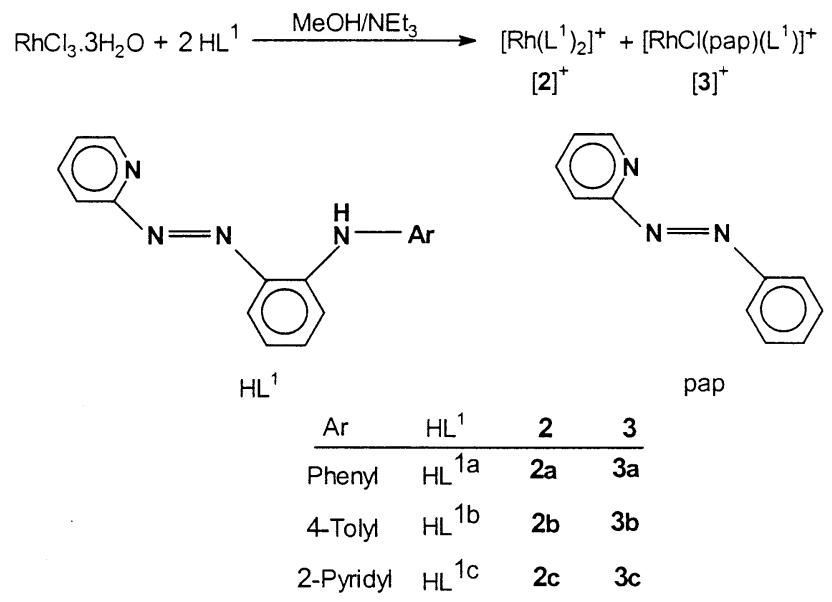

ligand $\mathrm{HL}^{1}$ was obtained ${ }^{13}$ by the regioselective orthoaromatic amination of coordinated pap ligand to a cobalt(II) center. The reaction (Scheme 2) in boiling methanol produced a green solution in about 4 h. Two green products 2 and 3 were isolated from the crude mixture on a preparative silica gel thin-layer chromatographic (TLC) plate. The presence of dilute $\mathrm{NEt}_{3}$ is necessary for the above reaction; otherwise the yields of the products $\mathbf{2}$ and $\mathbf{3}$ become negligible. These cationic compounds were obtained as their chloride salts, and the complexes $\mathbf{2 c}$ and $\mathbf{3 a}$ were found ${ }^{14}$ to be suitable for X-ray structural work.

Compound $\mathbf{2}$ was eluted as the first green band with chloroform-acetonitrile (2:1) mixture as the eluent and was obtained in ca. 35\% yield. The ORTEP plot and atom numbering scheme for the cationic part of $\mathbf{2 c}$ are shown in Figure 1. Selective bond distances are collected in Table 1. The structural analysis of the cationic $\left[\mathrm{Rh}\left(\mathrm{L}^{1 \mathrm{c}}\right)_{2}\right]^{+}$reveals the presence of two $\left[\mathrm{L}^{1 \mathrm{c}}\right]^{-}$ligands, each of which acts as an $N, N, N$-tridentate donor with deprotonation of the amine nitrogens, viz. $\mathrm{N}(2)$ and $\mathrm{N}(7)$. The pyridyl nitrogens $\mathrm{N}(1)$ and $\mathrm{N}(6)$ remain uncoordinated. The geometry of the cationic complex is meridional, and the $\mathrm{Rh}$ atom sits on an imposed $C_{2}$ axis bisecting the angles $\mathrm{N}(5)-\mathrm{Rh}-\mathrm{N}(10)$ and $\mathrm{N}(2)-$ $\mathrm{Rh}-\mathrm{N}(7)$. The two azo nitrogen atoms of the anionic tridentate ligands approach the metal center more closely $[\mathrm{Rh}-\mathrm{N}(3) / \mathrm{N}(8)$ average $1.962(4) \AA]$ than the other four $\mathrm{Rh}-\mathrm{N}$ bonds. There is an indication of significant backbone conjugation in the coordinated $\left[\mathrm{L}^{1 \mathrm{c}}\right]^{-}$ligand. Thus the $\mathrm{N}=$ $\mathrm{N}$ azo distances (average 1.291(5) $\AA$ ) in this complex are appreciably elongated. The main features of the structure of $2 c$ are similar to those for the complexes ${ }^{11,13}$ of $\left[\mathrm{L}^{1 \mathrm{a}}\right]^{-}$ involving 3d-metal ions, $\left[\mathrm{M}\left(\mathrm{L}^{1}\right)_{2}\right]^{+}[\mathrm{M}=\mathrm{Co}(\mathrm{III}), \mathrm{Fe}(\mathrm{III})]$.

The second green band was eluted by the same solvent mixture and was obtained in ca. $30 \%$ yield. The color of this $\mathbf{3}$ is similar to that of compound $\mathbf{2}$. The compound $\mathbf{3 a}$ formed suitable X-ray quality crystals for structure determination. Figure 2 shows the ORTEP plot and atom

(13) Saha, A.; Majumdar, P.; Goswami, S. J. Chem. Soc., Dalton Trans 2000, 1703.

(14) After repeated trials we could grow X-ray quality crystals of $\mathbf{2 c}$. The compounds $\mathbf{2 a}$ and $\mathbf{2 b}$ are crystalline but did not produce suitable X-ray quality crystals.

7126 Inorganic Chemistry, Vol. 41, No. 26, 2002 


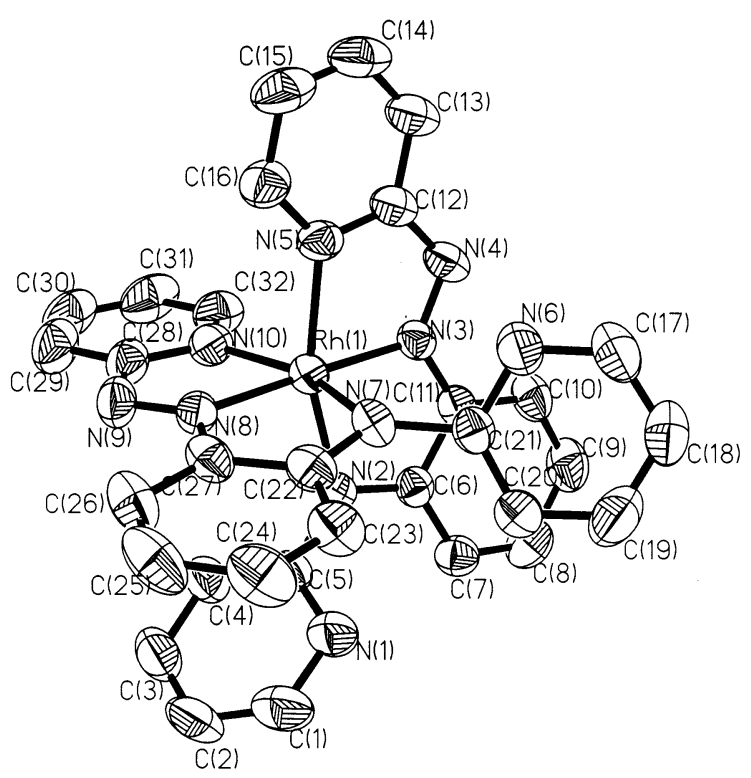

Figure 1. ORTEP plot and atom numbering scheme for the cationic part of the complex 2c. Hydrogen atoms are not shown for clarity.

Table 1. Selected Bond Distances $(\AA)$

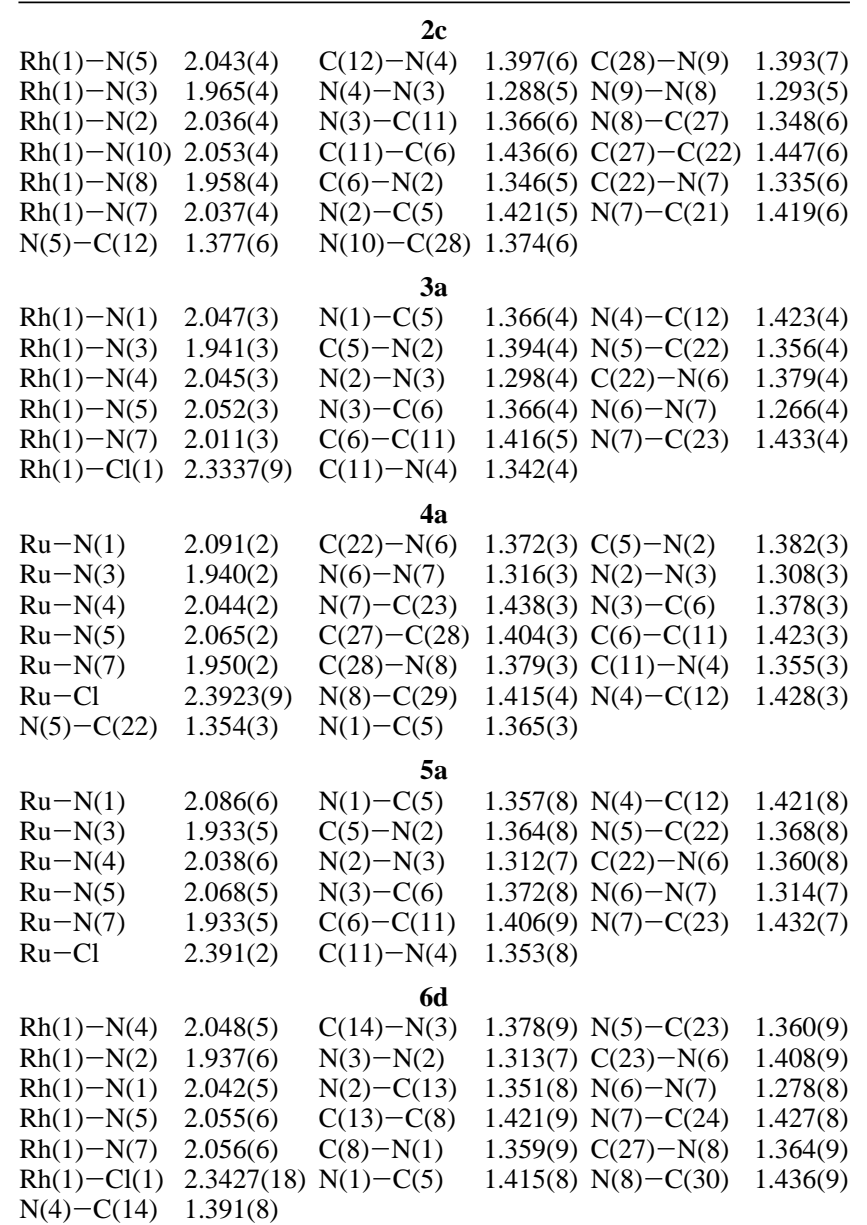

numbering scheme for the cationic part of the salt $\mathbf{3 a}$. Analysis of the crystal structure indeed authenticated the formation of a mixed ligand compound, $\left[\mathrm{RhCl}(\mathrm{pap})\left(\mathrm{L}^{1}\right)\right]^{+}$, from the reaction as shown in Scheme 2. One of the two $\mathrm{HL}^{1}$ ligands here has undergone a deamination reaction with the cleavage of a $\mathrm{C}-\mathrm{N}$ bond to form the bidentate neutral

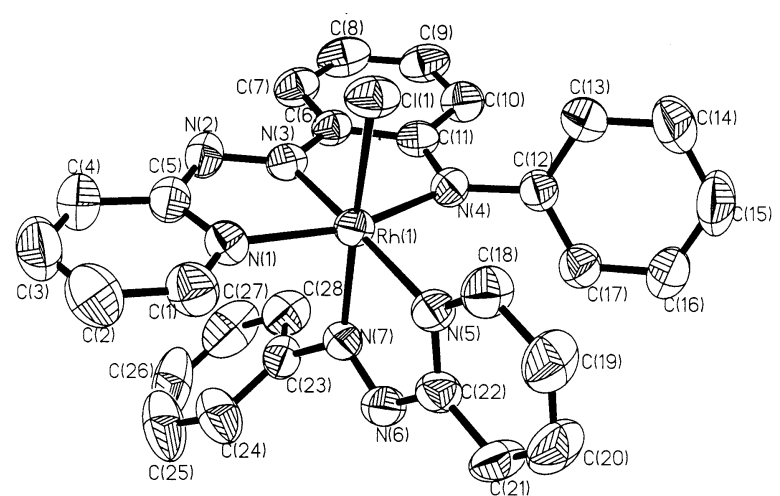

Figure 2. ORTEP plot and atom numbering scheme for the cationic part of the complex 3a. Hydrogen atoms are not shown for clarity.

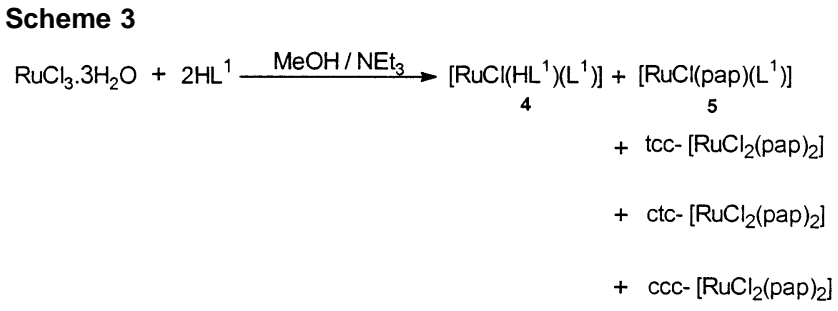

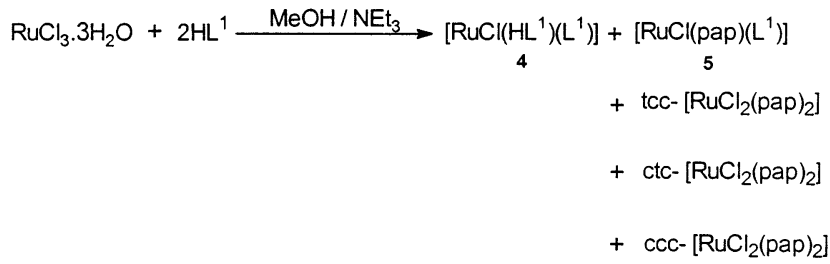

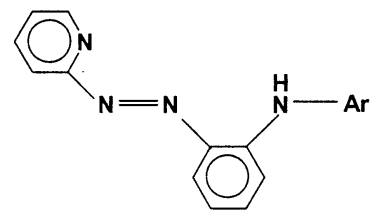

\begin{tabular}{cccc} 
Ar & $H L^{1}$ & $\mathbf{4}$ & $\mathbf{5}$ \\
\hline Phenyl & $H L^{1 a}$ & $4 a$ & $5 a$ \\
4-Tolyl & $H L^{1 b}$ & $4 b$ & $5 b$
\end{tabular}

$\mathrm{HL}^{1}$

pap ligand. Notably, the relative geometry of the pairs of azo nitrogens in $\mathbf{2}$ is trans while that in $\mathbf{3}$ is cis. Finally, we wish to note that the $\mathrm{N}-\mathrm{N}$ distance in the anionic extended ligand $\left[\mathrm{L}^{1 \mathrm{a}}\right]^{-}$is appreciably longer $[\mathrm{N}(2)-\mathrm{N}(3), 1.298(4) \AA]$ than that $[\mathrm{N}(6)-\mathrm{N}(7), 1.266(4) \AA]$ in the neutral pap ligand. This is attributed to the strong electron delocalization in $\left[\mathrm{L}^{1 \mathrm{a}}\right]^{-}$along the ligand backbone. Selected bond distances are collected in Table 1. Moreover, we wish to note here that the $\mathrm{M}-\mathrm{N}$ distances with the middle nitrogen of coordinated terpyridyl and other related $\mathrm{N}, \mathrm{N}, \mathrm{N}$ donors are usually shorter than the other two $\mathrm{M}-\mathrm{N}$ lengths. ${ }^{15,16} \mathrm{How}$ ever, there is no indication of $\pi$-interactions between rhodium(III) and the neutral pap ligand.

During chromatographic purification, a small dark green brown band remained uneluted near the spot, which could not be purified so far.

Reaction of Preformed $\mathrm{HL}^{1}$ and $\mathrm{RuCl}_{3} \cdot \mathbf{3} \mathrm{H}_{2} \mathrm{O}$. The reaction of hydrated $\mathrm{RuCl}_{3}$ with $\mathrm{HL}^{1}$ in boiling methanol in the presence of dilute $\mathrm{NEt}_{3}$ produced a brown solution in about $5 \mathrm{~h}$. Two new brown compounds 4 and 5 and three isomers of the known $\left[\mathrm{RuCl}_{2}(\text { pap })_{2}\right]$ were isolated from the crude product using a preparative TLC separation technique (Scheme 3). Compound $\mathbf{4}$ was eluted as the first brown band

(15) (a) Britovsek, G. J. P.; Gibson, V. C.; Kimberley, B. S.; Mastroianni, S.; Redshaw, C.; Solan, G. A.; White, A. J. P.; Williams, D. J. J. Chem. Soc., Dalton Trans. 2001, 1639. (b) Cadierno, V.; Gamasa, M. P.; Gimeno, J.; Iglesias, L.; García-Granda, S. Inorg. Chem. 1999, 38, 2874. (c) Pramanik, N. C.; Pramanik, K.; Ghosh, P.; Bhattacharya, S. Polyhedron 1998, 17, 1525 .

(16) Jahng, Y.; Thummel, R. P.; Bott, S. G. Inorg. Chem. 1997, 36, 3133. 
Das et al.

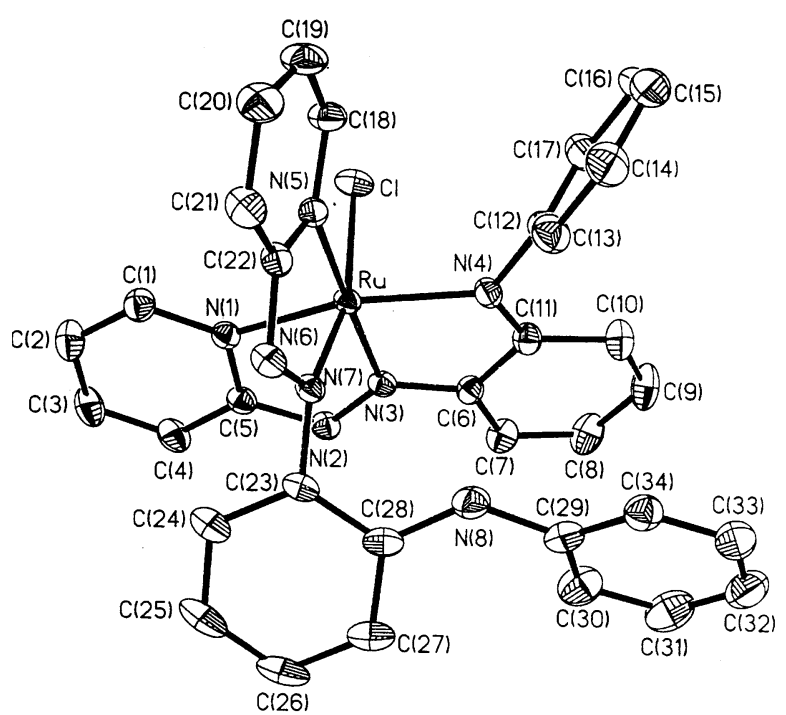

Figure 3. ORTEP plot and atom numbering scheme for the molecular complex 4a. Hydrogen atoms are not shown for clarity.

with benzene-chloroform mixture (3:2) as the eluent and was obtained in ca. $10 \%$ yield. The unsubstituted compound 4a formed suitable X-ray quality crystals for structure determination. An ORTEP plot along with atom numbering scheme for $\mathbf{4 a}$ is shown in Figure 3. It shows that the coordination modes of attachment of the two ligands to the central ruthenium(II) ion are different. While one of these acts as a monoanionic tridentate ligand and chelates through $\mathrm{N}(1), \mathrm{N}(3)$, and $\mathrm{N}(4)$, the other one acts as a neutral tridentate ligand and chelates to the metal ion via pyridine nitrogen $\mathrm{N}(5)$ and the azo nitrogen $\mathrm{N}(7)$. The neutral ligand thus bears a pendant arylamino group. The sixth coordination site of the central metal ion is occupied by a chloride ion providing a distorted octahedral $\left[\mathrm{RuN}_{5} \mathrm{Cl}\right]$ coordination environment. The relative positions of the pairs of pyridyl nitrogen and azo nitrogen in this complex are both cis. In this geometry, the amine $\mathrm{N}(8)$ is far from the metal center for coordination. Notably, the relative orientations of the coordinated atoms in $\mathbf{4}$ are different from that in the rhodium complex $\mathbf{2}$. The extensive $\pi$-bonding from metal to ligand in $\mathbf{4 a}$ is clear from the bond distance data of the compound (Table 1). Among the five $\mathrm{Ru}-\mathrm{N}$ bonds the two $\mathrm{Ru}-\mathrm{N}($ azo $)$ bonds, viz. $\mathrm{Ru}-$ $\mathrm{N}(3)$ and $\mathrm{Ru}-\mathrm{N}(7)$, are shorter compared to other three $\mathrm{Ru}-\mathrm{N}$ bonds. The $\mathrm{N}-\mathrm{N}$ distances [1.308(3) $\AA(\mathrm{N}(2)-\mathrm{N}(3))$ and 1.316(3) $\AA(\mathrm{N}(6)-\mathrm{N}(7))]$ are longer ${ }^{17}$ than those in [papH] $\mathrm{ClO}_{4}$. These facts are indications of (a) delocalization of electronic charge of the anionic ligand, $\left[\mathrm{L}^{1}\right]^{-}$, along the ligand backbone and (b) strong $\pi$-interactions between the metal d-orbitals and the neutral ligand $\left[\mathrm{HL}^{1}\right]$ via its azo functionality.

The color of compound $\mathbf{5}$ is also brown; $\mathbf{5}$ was separated from the first brown band $\mathbf{4}$ on a preparative silica gel TLC plate using same solvent mixture as the eluent. These two bands overlap each other and were separated only upon allowing sufficient time for the separation. This was obtained in ca. 20\% yield. Elemental analysis of compound $\mathbf{5}$ and its

(17) Saha, A.; Das, C.; Peng, S.-M.; Goswami, S. Indian J. Chem., Sect. A 2001, 40, 198.

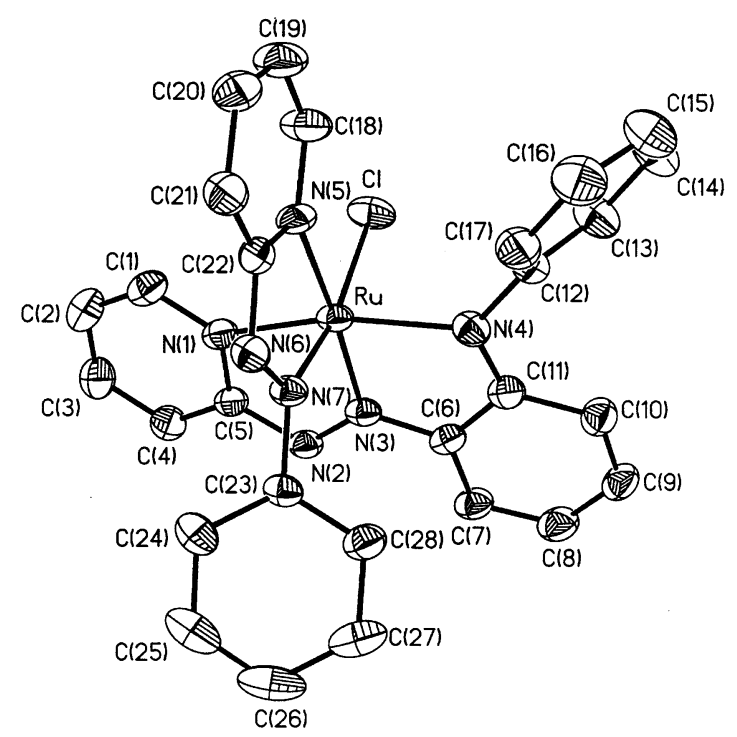

Figure 4. ORTEP plot and atom numbering scheme for the molecular complex 5a. Hydrogen atoms are not shown for clarity.

${ }^{1} \mathrm{H}$ NMR spectra indicated the loss of an aromatic amine group from the ligand. The structural analysis of $\mathbf{5 a}$ revealed that its composition corresponds to a mixed ligand complex, $\left[\mathrm{RuCl}(\mathrm{pap})\left(\mathrm{L}^{1 \mathrm{a}}\right)\right]$. In this compound, the ligand pap is formed due to deamination of $\mathrm{HL}^{1 \mathrm{a}}$. The physicochemical properties of this compound are similar to those of compound 4. Also, bond distances data (Table 1) show similar strong metalligand $\pi$-interactions. The ORTEP plot and atom numbering scheme for 5a are shown in Figure 4. It may be noted here that the geometry of the molecular complex $\mathbf{5}$ is identical to that of the cationic rhodium complex 3 . It may be relevant to compare the bond lengths of the two related complexes 3a and 5a. In these two complexes, the metal centers are surrounded by a distorted octahedral coordination environment with one chloride ligand, the bidentate neutral chelating ligand, pap, and the tridentate monoanionic bischelating ligand, $\left[\mathrm{L}^{1 \mathrm{a}}\right]^{-}$. The bond lengths of both $\mathbf{3 a}$ and $\mathbf{5 a}$, along the ligand backbone of the coordinated $\left[\mathrm{L}^{1 \mathrm{a}}\right]^{-}$, indicate extensive delocalization. As a result, (a) the $\mathrm{N}=\mathrm{N}$ lengths are elongated, (b) azo nitrogen to phenyl carbon lengths are shorter than those in pap, and (c) the bond lengths of amine nitrogens to the phenyl group of pap are shorter than a $\mathrm{C}-\mathrm{N}$ single bond. However, such delocalization was not observed in the neutral pap ligand. Interestingly, the $\mathrm{Ru}-\mathrm{N}$ (azo, pap) distance, in 5a, is notably shorter than the $\mathrm{Ru}-\mathrm{N}$ (py, pap) distance. Moreover, the $\mathrm{N}-\mathrm{N}$ distance (pap) is elongated appreciably. This is attributed to strong $\mathrm{d} \pi-\mathrm{p} \pi$ interactions between $\mathrm{Ru}(\mathrm{II})$ and $\pi^{*}$ (azo) of pap. Such metal-ligand interaction was, however, absent in 3a. In this compound $\mathrm{Rh}-\mathrm{N}$ (azo, pap) and $\mathrm{Rh}-\mathrm{N}$ (py, pap) lengths are comparable and consequently the $\mathrm{N}-\mathrm{N}$ distance (pap) retains its double bond character. ${ }^{17}$

Besides the aforementioned two brown compounds, the three known isomers of $\left[\mathrm{RuCl}_{2}(\text { pap })_{2}\right]$, viz. $t c c-\left[\mathrm{RuCl}_{2}(\text { pap })_{2}\right]$, $c t c$ - $\left.\left[\mathrm{RuCl}_{2} \text { (pap) }\right)_{2}\right]$, and $c c c$-[ $\left[\mathrm{RuCl}_{2}(\text { pap })_{2}\right]$, were also formed. These were separated on a silica gel TLC plate using chloroform as the eluent. The yields of these compounds varied between 5\% and 10\%. Their spectroscopic and 


\section{Scheme 4}

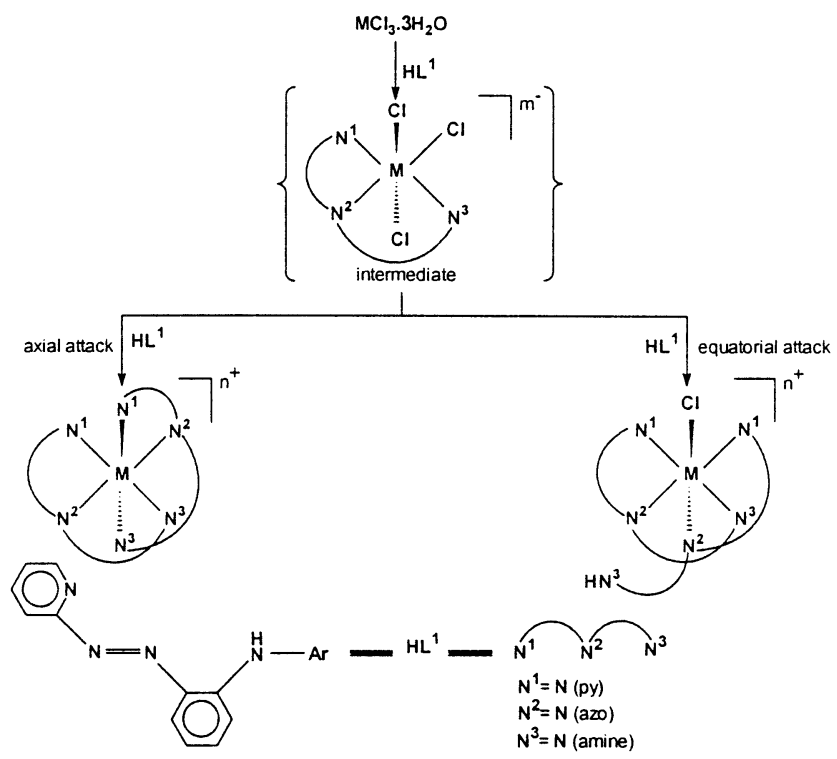

voltammetric data exactly corresponded to those of the authentic samples of the known isomeric $\left.\left[\mathrm{RuCl}_{2} \text { (pap) }\right)_{2}\right]$. We also noted a few more minor bands on the TLC plate; none of these produced any detectable pure compound. In the above synthetic reaction involving $\mathrm{RuCl}_{3} \cdot 3 \mathrm{H}_{2} \mathrm{O}$ and $\mathrm{HL}^{1}$, the starting trivalent ruthenium salt underwent one-electron reduction in methanol. The mechanism and the byproducts of the above reduction $[\mathrm{Ru}(\mathrm{III}) \rightarrow \mathrm{Ru}(\mathrm{II})]$ are not established. However, we believe that complex formation followed by reduction ${ }^{18}$ would be a plausible path for the formation of bivalent ruthenium complexes.

Except for the first brown compound 4, the rest of the ruthenium compounds, described above, are obtained due to the cleavage of at least one $\mathrm{C}$ (phenyl) $-\mathrm{N}$ (amine) bond in $\mathrm{HL}^{1}$. This organic transformation was not observed in the absence of metal ion.

Comparison between Schemes 2 and 3. The two types of products of undissociated $\mathrm{HL}^{1} /\left[\mathrm{L}^{1}\right]^{-}$were obtained from the above two reactions. While in the case of ruthenium one of the two coordinated ligands does not use its maximum denticity, the ligands are symmetrically chelated in the rhodium complex, $\left[\mathrm{Rh}\left(\mathrm{L}^{1}\right)_{2}\right]^{+}$. It is known ${ }^{16}$ that the substitution reactions in $\left[\mathrm{MCl}_{3} \cdot 3 \mathrm{H}_{2} \mathrm{O}\right](\mathrm{M}=\mathrm{Ru}, \mathrm{Rh})$ proceed stepwise. Thus the product $\left\{\left[\mathrm{MCl}_{3} \mathrm{~L}^{1}\right]^{m-}\right\}$ may be viewed as the intermediate complex for the above reactions (Scheme 4). This intermediate complex has one equatorial and two axial leaving groups $(\mathrm{Cl})$, which are substituted by another $\mathrm{HL}^{1} /\left[\mathrm{L}^{1}\right]^{-}$to form the final product. An axial attack by the terminal pyridyl(N) at the intermediate complex would produce a bischelate $\left[\mathrm{M}\left(\mathrm{L}^{1}\right)_{2}\right]^{n+}$, whereas an equatorial attack would lead to the mixed ligand complex $\left[\mathrm{MCl}\left(\mathrm{HL}^{1}\right)\left(\mathrm{L}^{1}\right)\right]^{n+}$. Thus it may be concluded that while axial attack is favored in the case of rhodium, the equatorial attack is preferred for ruthenium. It may be recalled here that in all its known complexes ${ }^{11,13}$ with $3 \mathrm{~d}$-metal ions, the ligand, under consid-

(18) (a) Goswami, S.; Chakravarty, A. R.; Chakravorty, A. Inorg. Chem. 1981, 20, 2246. (b) Choudhury, S.; Kakoti, M.; Deb, A. K.; Goswami, S. Polyhedron 1992, 11, 3183. eration, binds as an anionic tridentate donor to yield metal complexes of the general formula $\left[\mathrm{M}\left(\mathrm{L}^{1}\right)_{2}\right]^{n+}$. In order to look for the differences, we also note that trans-N(azo), $\mathrm{N}$ (azo) pair orientation ${ }^{19,20}$ has never been observed in the ruthenium(II) complexes of pap ligands. The trans-M[N(azo), $\mathrm{N}(\mathrm{azo})$ ] grouping is however, an essential prerequisite for the formation of $\left[\mathrm{M}\left(\mathrm{L}^{1}\right)_{2}\right]^{n+}$ complex. Unlike the 3d-metal ions, the ruthenium(II) ion is known to enter into $\pi$-interactions effectively with the low-lying $\pi^{*}$ (ligand) orbitals. Thus, very strong $\mathrm{d} \pi-\operatorname{azo}\left(\pi^{*}\right)$ back-bonding is a persistent feature in $\mathrm{Ru}(\mathrm{II})$ - pap chelates. In the trans-N(azo), N(azo) pair geometry, the $\pi^{*}$ (azo) orbitals compete for the same metal $\mathrm{d} \pi$ orbital, which weakens back-bonding. The rhodium(III) ion, on the other hand, is not a good $\pi$-donor and behaves like 3d-metal ions. Notably, osmium(II) also behaves ${ }^{21}$ like ruthenium(II) in its reaction with $\mathrm{HL}^{1}$.

Compounds $\mathbf{3}$ and $\mathbf{5}$ and the three isomers of $\left[\mathrm{RuCl}_{2}(\mathrm{pap})_{2}\right]$ are formed due to cleavage 22 of at least one $\mathrm{C}$ (phenyl)$\mathrm{N}$ (amine) bond. The mechanism for this bond cleavage reaction has not been elucidated. We note here that the ligand $\mathrm{HL}^{1}$ reacts spontaneously with $3 \mathrm{~d}$-metal ions, where no such $\mathrm{C}-\mathrm{N}$ bond cleavage was observed. ${ }^{11,13}$

Amination Reaction. The mixed ligand complexes [MCl$\left.(\operatorname{pap})\left(\mathrm{L}^{1}\right)\right]^{n+}\left(\mathrm{M}=\mathrm{Rh}^{\mathrm{III}}, \mathbf{3}(n=1) ; \mathrm{M}=\mathrm{Ru}^{\mathrm{II}}, \mathbf{5}(n=0)\right)$ contain coordinated pap ligand, and it was anticipated ${ }^{9}$ that these might be suitable substrates for amination reactions. In line with our strategy, both the complexes $\mathbf{3 a}$ and $\mathbf{5 a}$ were reacted with $\mathrm{ArNH}_{2}$ neat and in the presence of air. While compound 3a reacted instantaneously to produce an ink blue product, the corresponding ruthenium complex 5a is unreactive to $\mathrm{ArNH}_{2}$. Compounds 3a and 5a are similar except that the former is cationic while the latter is a molecular complex. Although $[\mathbf{5 a}]^{+}$can be generated in solution by the exhaustive electrolysis of $\mathbf{5 a}$, we could not isolate $[\mathbf{5 a}]^{+}$ in its pure state. Thus it is concluded that amination reaction is facilitated ${ }^{23}$ in a cationic complex, whose electrophilicity is higher than that for a molecular complex. Interestingly, the ink blue product, obtained from the reaction of $\mathbf{3 a}$ and $\mathrm{ArNH}_{2}$, is similar to the product obtained directly from the reaction of $\left.\left[\mathrm{RhCl}_{2} \text { (pap) }\right]_{2}\right]^{+}$and $\mathrm{ArNH}_{2}$. It was proposed ${ }^{9,24}$ that dissociation of a chloride ion from $\left[\mathrm{RhCl}_{2}(\text { pap })_{2}\right]^{+}$creates a vacant site and is hence responsible for ortho-amination of one of the two pap ligands in the starting rhodium dichloro complex. The second chloride ion could not be dissociated under our experimental conditions, and hence the amination

(19) (a) Seal, A.; Ray, S. Acta Crystallogr., Sect. C 1984, 40, 929. (b) Krause, K.; Krause, R. A.; Larsen, S.; Rasmussen, B. Acta Chem. Scand. Ser. A 1985, 39, 375. (c) Majumdar, P.; Peng, S.-M.; Goswami, S. J. Chem. Soc., Dalton Trans. 1998, 1569. (d) Velders, A. H.; Kooijman, H.; Spak, A. L.; Haasnoot, J. G.; Vos, D. de; Reedijk, J. Inorg. Chem. 2000, 39, 2966.

(20) Ghosh, B. K.; Mukhopadhyay, A.; Goswami, S.; Ray, S.; Chakravorty, A. Inorg. Chem. 1984, 23, 4633 .

(21) Das, C.; Peng, S.-M.; Lee, G.-H.; Goswami, S. New J. Chem. 2002, $26,222$.

(22) (a) Bhattacharyya, S.; Weakley, T. J. R.; Chaudhury, M. Inorg. Chem. 1999, 38, 5433. (b) Gray, S. D.; Weller, K. J.; Bruck, M. A.; Briggs, P. M.; Wigley, D. E. J. Am. Chem. Soc. 1995, 117, 10678.

(23) Kamar, K. K.; Saha, A.; Castiñeiras, A.; Hung, C.-H.; Goswami, S. Inorg. Chem. 2002, 41, 4531. Das, C.; Saha, A.; Hung, C.-H.; Lee G.-H.; Peng, S.-M.; Goswami, S. Inorg. Chem. 2003, 42, 0000.

(24) Deb, A. K.; Goswami, S. J. Chem. Soc., Dalton Trans. 1989, 1635. 
Das et al.

Table 2. Spectral Data

\begin{tabular}{|c|c|c|c|c|}
\hline \multirow[b]{2}{*}{ compd } & \multicolumn{3}{|c|}{$\mathrm{IR},{ }^{a} \mathrm{~cm}^{-1}$} & \multirow[b]{2}{*}{ absorption $^{b} \lambda_{\max }, \mathrm{nm}\left(\epsilon, \mathrm{M}^{-1} \mathrm{~cm}^{-1}\right)$} \\
\hline & $v(\mathrm{~N}-\mathrm{H})$ & $\nu(\mathrm{C}=\mathrm{N})$ & $v(\mathrm{~N}=\mathrm{N})$ & \\
\hline 2a & & 1600 & 1310 & $890(7370), 795(11350), 725(11240), 655^{c} 440 c^{c} 350(19890), 25^{d}(36160)$ \\
\hline 2b & & 1595 & 1325 & $900(6270), 800(9710), 735(9520), 660,^{c} 435,^{c} 355(16120), 265^{d}(30930)$ \\
\hline 2c & & 1595 & 1310 & 885 (5670), 790 (8960), $715(8240), 645,^{c} 430,{ }^{c} 350(15800), 275(23560)$ \\
\hline 3a & & 1610 & 1320,1435 & $895(3870), 800(6840), 730(6330), 660, c^{c} 360(18320), 265^{d}(25250)$ \\
\hline 3b & & 1610 & 1320,1430 & $900(3280), 800(5770), 735(5360), 665,{ }^{c} 365(15250), 265^{d}(21640)$ \\
\hline $3 c$ & & 1600 & 1310,1435 & 890 (3090), 790 (5610), $720(4790), 650, c 350$ (13 140), 275 (16 390) \\
\hline $4 \mathbf{a}$ & 3390 & 1595 & 1233,1295 & $950^{d}(3310), 830(4380), 555^{d}(6190), 470(9410), 375,{ }^{c} 290(29180)$ \\
\hline 4b & 3405 & 1595 & 1230,1275 & $960^{d}(3150), 830(4340), 555^{d}(6350), 470(9420), 390,^{c} 290(29330)$ \\
\hline $5 \mathbf{a}$ & & 1595 & 1230,1275 & $970^{d}(3450), 850(4450), 555(7050), 475(10280), 300(22030)$ \\
\hline $5 \mathbf{b}$ & & 1595 & 1225,1270 & $990^{d}(3620), 850(5060), 550(7400), 475(10980), 300(23080)$ \\
\hline 6a & 3410 & 1585 & 1310,1435 & $910(3020), 805(5500), 605(28910), 395,{ }^{c} 355^{d}(11620), 270$ (25 230) \\
\hline $\mathbf{6 b}$ & 3400 & 1585 & 1310,1440 & $915(2820), 810(5150), 605(25500), 400,{ }^{c} 350^{d}(10500), 280(21600)$ \\
\hline 6c & 3405 & 1585 & 1315,1440 & $910(2910), 805(5500), 605(24860), 400,{ }^{c} 360$ (11 830), 275 (26 560) \\
\hline 6d & 3410 & 1590 & 1315,1440 & $910(2720), 805(4940), 610(27660), 395,^{c} 340^{d}(16260), 270$ (26 920) \\
\hline
\end{tabular}

${ }^{a}$ In $\mathrm{KBr}$ disk. ${ }^{b}$ In acetonitrile. ${ }^{c}$ Ill-defined shoulder. ${ }^{d}$ Shoulder.

Scheme 5

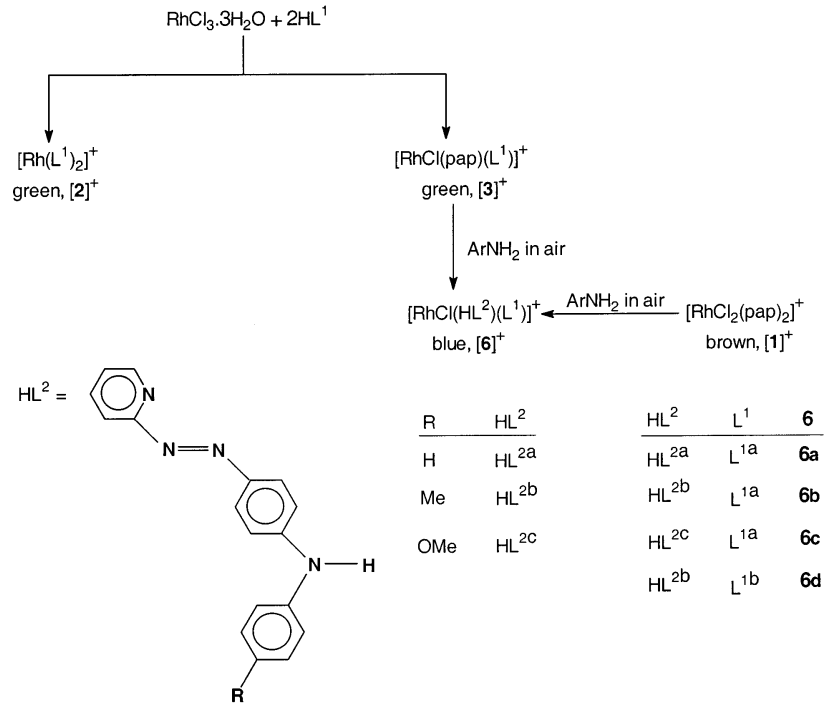

of the second pap in the said complex occurs at the para position as the second choice. Our present results have indeed confirmed our proposition. Compound $\mathbf{3}$, in fact, is the proposed intermediate for the transformation $\left[\mathrm{RhCl}_{2}(\mathrm{pap})_{2}\right]^{+}$ $\rightarrow\left[\mathrm{RhCl}\left(\mathrm{HL}^{2}\right)\left(\mathrm{L}^{1}\right)\right]^{+}\left([\mathbf{1}]^{+} \rightarrow[\mathbf{6}]^{+}\right)$. The results have been summarized in Scheme 5.

The reaction of $\mathbf{3 a}$ with three different aromatic amines, $\mathrm{ArNH}_{2}\left(\mathrm{ArNH}_{2}=\right.$ aniline, $p$-toluidine, and $p$-anisidine $)$ produced a deep blue mixture, which on chromatographic purification yielded the ink blue crystalline compound $\mathbf{6}$ in $>75 \%$ yield. The compound $\left[\mathrm{RhCl}\left(\mathrm{HL}^{2 \mathrm{~b}}\right)\left(\mathrm{L}^{1 \mathrm{~b}}\right)\right]\left(\mathrm{PF}_{6}\right)(\mathbf{6 d})$ formed crystals suitable for the determination of its $\mathrm{X}$-ray structure. In this complex, the extended ligand $\mathrm{HL}^{2 \mathrm{~b}}$ is neutral and is formed due to fusion of $p$-toluidine fragment to the coordinated pap ligand in $\mathbf{3} \mathbf{b}$ at the para position (relative to the azo fragment) of the phenyl group of pap. This acts as a bidentate ligand and chelates to rhodium through the pyridine nitrogen $\mathrm{N}(5)$ and the azo nitrogen $\mathrm{N}(7)$. The amine nitrogen atom $\mathrm{N}(8)$ of this bears a hydrogen atom and remains uncoordinated. The bidentate $\mathrm{HL}^{2 \mathrm{~b}}$ and anionic tridentate $\left[\mathrm{L}^{1 b}\right]^{-}$along with one chloride ion complete a distorted octahedral environment about rhodium. ${ }^{9}$ A comparison of bond distance data in this molecule (Table 1) indicates different levels of conjugation in the two coordinated ligands. For example, the $\mathrm{N}-\mathrm{N}$ distance for the neutral $\mathrm{HL}^{2 \mathrm{~b}}, \mathrm{~N}(6)-\mathrm{N}(7)$, is $1.278(8) \AA$ while the corresponding distance in the anionic tridentate ligand $\left[\mathrm{L}^{1 \mathrm{~b}}\right]^{-}, \mathrm{N}(2)-\mathrm{N}(3)$, is $1.313(7) \AA$. Taken together, the lengthening of the azo $\mathrm{N}=\mathrm{N}$ distance in $\left[\mathrm{L}^{1 b}\right]^{-}$and the foreshortening of the $\mathrm{N}-\mathrm{C}$ distances alongside the azo moiety, with respect to the corresponding distances in $\mathrm{HL}^{2 \mathrm{~b}}$ itself, indicate greater delocalization of $\pi$-electron density in $\left[\mathrm{L}^{1 \mathrm{~b}}\right]^{-}$. The central $\mathrm{Rh}-\mathrm{N}$ bond of the anionic ligand, $\mathrm{Rh}(1)-\mathrm{N}(2)=1.937(6)$ $\AA$, is significantly shorter than the other four $\mathrm{Rh}-\mathrm{N}$ lengths, which are all near their average value of 2.050(5) $\AA$.

Furthermore, the mixed rhodium(III) complex [ $\mathrm{RhCl}(\mathrm{pap})-$ $\left.\left(\mathrm{L}^{1}\right)\right]^{+}(3)$ is substitutionally inert, from which chloride ion dissociation was not possible. The amination reaction in this substitutionally inert complex occurs exclusively at the para carbon of the pendant phenyl ring of coordinated pap.

Spectral Properties. Selected spectral data are collected in Table 2. The features of the IR spectra of the complexes are closely similar to those of the reported examples. ${ }^{9,11,13}$ The $\mathrm{N}=\mathrm{N}$ stretching frequencies are lowered. The ${ }^{1} \mathrm{H} \mathrm{NMR}$ spectra of the bis chelated compounds, 2, are resolved. Notably, each kind of proton of the coordinated ligand $\left[\mathrm{L}^{1}\right]^{-}$ gave rise to one signal confirming the presence of a 2-fold symmetry axis. The rest of the compounds $3-6$ are all mixed ligand complexes that are coordinated by different ligands. As a result, these gave rise to complex spectral patterns due to the presence of large numbers of unique protons. While the methyl resonances of $\mathrm{HL}^{1 \mathrm{~b}}$ and $\mathrm{HL}^{2 \mathrm{~b}}$ appeared in the range $2.15-2.35 \delta$, in $\mathrm{HL}^{2 \mathrm{c}}\left(\mathrm{OCH}_{3}\right)$ it appeared near 3.90 $\delta$.

Figure 6 shows the solution spectra of the representative examples. Multiple low-energy transitions are the characteristics of all the spectra (Table 2). The solution color of the two rhodium complexes, viz. $\mathbf{2}$ and $\mathbf{3}$, are green while that for $\mathbf{6}$ is ink blue. The spectral patterns of the compounds $\mathbf{2}$ and $\mathbf{3}$ are similar except that the intensities of the lowenergy transitions $(900-650 \mathrm{~nm})$ for compound 2 are roughly double the intensities of similar transitions for compound, $\mathbf{3}$. It is to be noted here that while compound $\mathbf{2}$ is coordinated by the two anionic tridentate ligands $\left[\mathrm{L}^{1}\right]^{-}$, compound $\mathbf{3}$, on the other hand, has only one such ligand. 


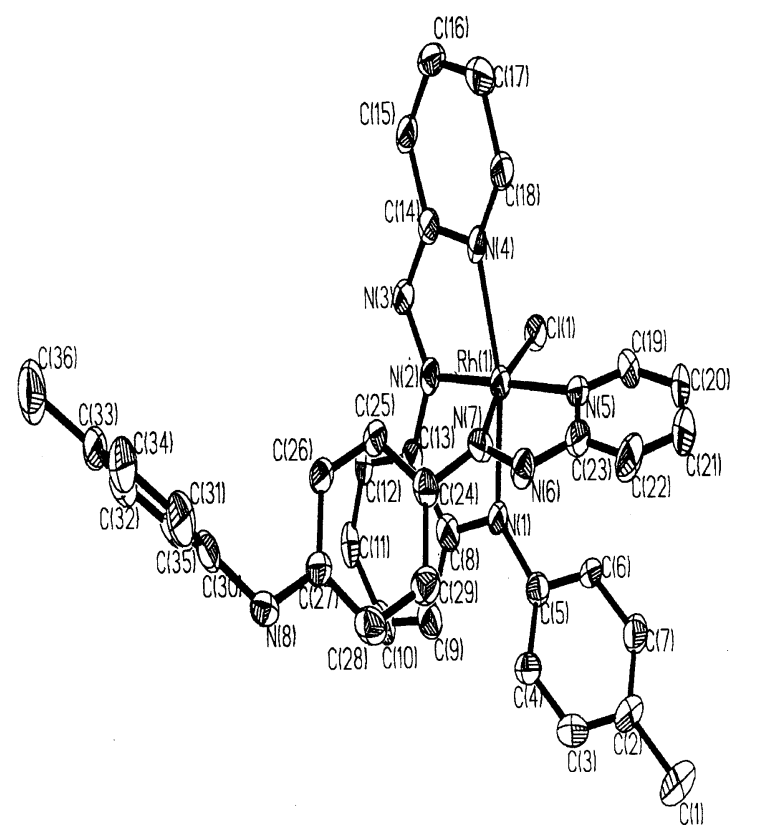

Figure 5. ORTEP plot and atom numbering scheme for the cationic part of the complex $\mathbf{6 d}$. Hydrogen atoms are not shown for clarity.

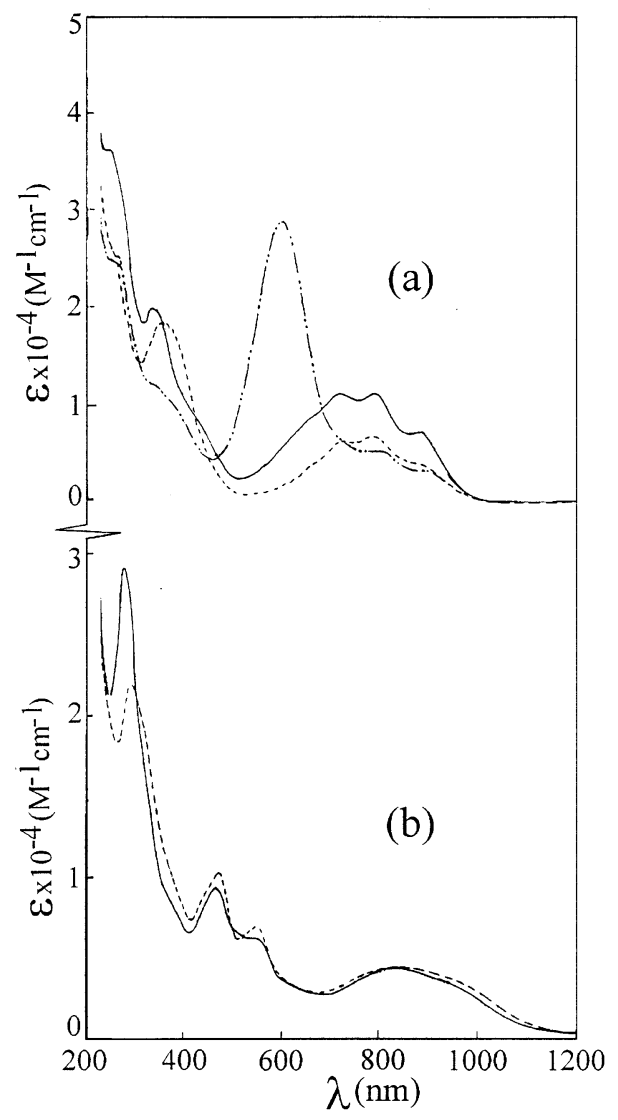

Figure 6. Electronic spectra of (a) 2a (-), 3a (---), and $\mathbf{6 a}(-\cdot--)$; and (b) $4 \mathbf{a}(-)$ and $5 \mathbf{a}(--)$.

These results tempt us to propose that these low-energy transitions in $\mathbf{2}$ and $\mathbf{3}$ involve orbitals that are predominantly ligand in character and originated primarily from the coordinated $\left[\mathrm{L}^{1}\right]^{-}$ligand part. We have performed extended Hückel MO calculations with the crystallographic parameters of $\mathbf{2 c}, \mathbf{3 a}$ and $\mathbf{6 d}$, using the CACAO program ${ }^{25}$ by Mealli and Proserpio. Due to the obvious limitations, we note that the results are qualitative in nature. However, the calculations have indicated that the HOMO and HOMO -1 orbitals in these complexes are predominantly ligand orbitals with only small contributions from the metal orbitals (Supporting Information Figure S1). The acceptor orbital LUMO is also a ligand orbital with ca. $20 \%$ contribution from the metal d-orbitals. Interestingly, on moving from 3 to $\mathbf{6}$ the spectral nature is completely changed (Figure 6a). Two low-energy transitions are observed in $\mathbf{6}$. The lowest energy transitions in the range $(900-800 \mathrm{~nm})$ are similar, in both intensity and energy, to that observed in $\mathbf{3}$. The transition near $730 \mathrm{~nm}$ (in 3), however, is replaced by a highly intense transition $(\epsilon$ $>25000 \mathrm{M}^{-1} \mathrm{~cm}^{-1}$ ) near $605 \mathrm{~nm}$, which is responsible for the intense ink blue color of compound $\mathbf{6}$. In fact, the blue color is characteristic ${ }^{23}$ of all the transition metal complexes that contain $\mathrm{HL}^{2}$ as a ligand. In the ligand, $\mathrm{HL}^{2}$, a donor amine group is separated from an acceptor azo function by a conjugated spacer. The acceptor ability of the azo chromophore is expected to be augmented on coordination. Hence the transition near $605 \mathrm{~nm}$ in the complexes 6 is assigned to an intraligand transition localized at the coordinated $\mathrm{HL}^{2}$ ligand. We wish to note here that such low-energy transitions in rhodium(III) complexes are virtually unknown. ${ }^{26}$

The spectra of the ruthenium complexes consist of similar two low-energy transitions in the range $(1000-820 \mathrm{~nm})$, which are red shifted compared to those of the rhodium(III) complexes. Notably, two additional strong transitions near 550 and $475 \mathrm{~nm}$ were also observable (Figure 6b). The ruthenium(II) complexes containing acceptor ligands in general show ${ }^{27}$ intense metal-to-ligand charge transfer (MLCT) in the visible region. The above transitions may be ascribed to MLCT transitions. Notably, in addition to the multiplestep ligand reductions, metal oxidation redox processes were observable only in the ruthenium complexes (vide infra).

Redox Properties. Both the free ligands $\mathrm{HL}^{1}$ and $\mathrm{HL}^{2}$ are known to undergo ${ }^{11}$ two-step reductions in the range -1.20 to $-2.00 \mathrm{~V}$. These also show an irreversible anodic wave near $1.05 \mathrm{~V}$ due to their oxidation.

The cyclic voltammograms of the rhodium complexes are dominated by the multiple step reduction processes (Table 3 , Figure 7). The anodic responses, on the other hand, are irreversible. All the redox processes in the rhodium complexes involve ${ }^{24}$ primarily ligand orbitals.

The voltammograms of the ruthenium complexes $\mathbf{4}$ and $\mathbf{5}$ are almost identical. In fact, the two ruthenium complexes are similar with the exception that in $\mathbf{4}$ an ortho-substituted ligand $\mathrm{HL}^{1}$ replaces the pap ligand. The $o$-arylamino substitution on pap appears to have a very minor effect on the redox and the spectral properties of the reference complexes. The cathodic responses in the ruthenium com-

(25) Mealli, C.; Proserpio, D. M. J. Chem. Educ. 1990, 67, 399.

(26) Cotton, F. A.; Wilkinson, G.; Murillo, C. A.; Bochmann, M. Advanced Inorganic Chemistry, 6th ed.; Wiley: New York, 1999; p 1048.

(27) (a) Kober, E. M.; Meyer, T. J. Inorg. Chem. 1982, 21, 3967. (b) Goswami, S.; Mukherjee, R.; Chakravorty, A. Inorg. Chem. 1983, 22, 2825 . 
Das et al.

Table 3. Cyclic Voltammetric Data ${ }^{a}$

\begin{tabular}{cll}
\hline compd & $E_{1 / 2},{ }^{b} \mathrm{~V}\left(\Delta E_{\mathrm{p}}, \mathrm{mV}\right)$ & \multicolumn{1}{c}{$-E_{1 / 2},{ }^{b} \mathrm{~V}\left(\Delta E_{\mathrm{p}}, \mathrm{mV}\right)$} \\
\hline $\mathbf{2 a}$ & $1.42^{c}$ & $0.48(70), 0.81(100), 1.45(120), 1.75(120)$ \\
$\mathbf{2 b}$ & $1.33^{c}$ & $0.50(70), 0.81(90), 1.43(100), 1.73(100)$ \\
$\mathbf{2 c}$ & $1.49^{c}$ & $0.43(60), 0.71(80), 1.35(100), 1.73(100)$ \\
$\mathbf{3 a}$ & $1.32^{c}$ & $0.07(90), 0.69(100), 1.43(100), 1.83(100)$ \\
$\mathbf{3 b}$ & $1.25^{c}$ & $0.21(90), 0.75(90), 1.18(100), 1.41(110)$ \\
$\mathbf{3 c}$ & $1.39^{c}$ & $0.10(70), 0.62(100), 1.32(100), 1.71(120)$ \\
$\mathbf{4 a}$ & $0.46(90), 1.42^{d}$ & $0.91,{ }^{e} 1.17,{ }^{e} 1.72^{e}$ \\
$\mathbf{4 b}$ & $0.45(70), 1.40^{d}$ & $0.90,{ }^{e} 1.14,{ }^{e} 1.70^{e}$ \\
$\mathbf{5 a}$ & $0.46(80), 1.25^{d}$ & $0.90(150), 1.87^{e}$ \\
$\mathbf{5 b}$ & $0.45(100), 1.19(100)$ & $0.89,{ }^{d} 1.85^{e}$ \\
$\mathbf{6 a}$ & $1.33^{c}$ & $0.25(80), 0.58(120), 0.82(70)$, \\
& & $1.48(110), 1.80(130)$ \\
$\mathbf{6 b}$ & $1.30^{c}$ & $0.25(90), 0.54(120), 0.82(80)$, \\
& & $1.42(120), 1.76(140)$ \\
$\mathbf{6 c}$ & $1.26^{c}$ & $0.25(90), 0.55(110), 0.83(90)$, \\
& \multicolumn{1}{c}{$1.45(100), 1.75(120)$} \\
6d & $1.27^{c}$ & $0.25(90), 0.52(100), 0.80(70)$, \\
& & $1.50(90), 1.78(120)$
\end{tabular}

${ }^{a}$ Conditions: solvent, acetonitrile; supporting electrolyte, $\mathrm{NEtClO}_{4},(0.1$ $\mathrm{M}$ ); working electrode, platinum for oxidation and glassy carbon for reduction processes; reference electrode SCE; solute concentration, ca. $10^{-3}$ (M); scan rate, $50 \mathrm{mV} \mathrm{s}^{-1} \cdot{ }^{b} E_{1 / 2}$, the redox processes are reversible. $E_{1 / 2}$ is calculated as the average of anodic $\left(E_{\mathrm{pa}}\right)$ and cathodic $\left(E_{\mathrm{pc}}\right)$ peak potentials. $\Delta E_{\mathrm{p}}=E_{\mathrm{pa}}-E_{\mathrm{pc}}$ in $\mathrm{mV} .{ }^{c} E_{\mathrm{pa}}$, irreversible anodic response. ${ }^{d}$ Quasireversible. ${ }^{e} E_{\mathrm{pc}}$, irreversible cathodic response.
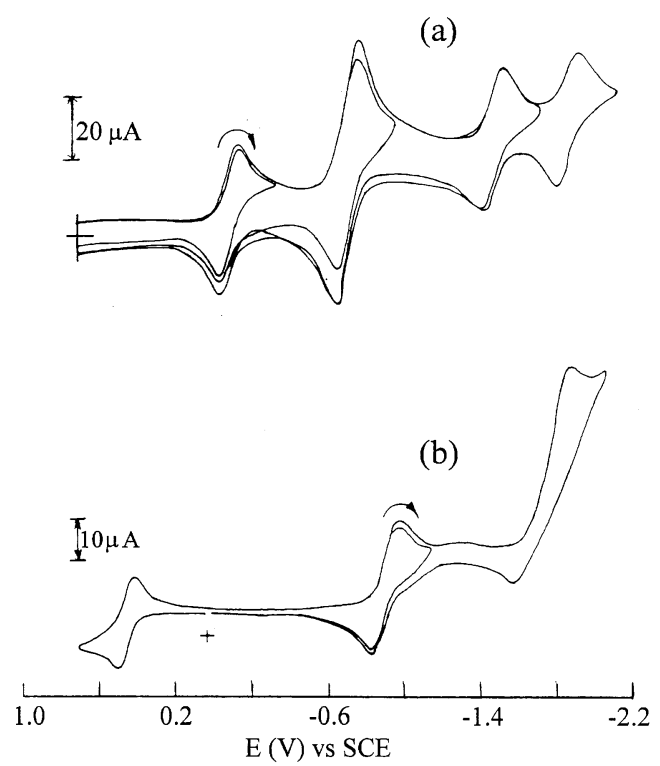

Figure 7. Segmented cyclic voltammograms of (a) $\mathbf{3 a}$ and (b) $\mathbf{5 a}$ in $\mathrm{CH}_{3^{-}}$ $\mathrm{CN}$ (0.1 M TEAP); scan rate $50 \mathrm{mV} \mathrm{s}^{-1}$.

plexes are also due to ${ }^{27-29}$ the reductions of the coordinated ligands. Notably, these responses shift anodic appreciably in the corresponding complexes of rhodium(III) (Table 3). This shift is due to higher electrophilicity of the cationic rhodium(III) complexes ${ }^{10}$ over the neutral ruthenium complexes. The first reversible oxidative anodic responses in the ruthenium(II) complexes near $0.45 \mathrm{~V}$ are due to the $\mathrm{Ru}^{\mathrm{II}}$ / $\mathrm{Ru}^{\mathrm{III}}$ redox process.

Low potentials of $\mathrm{Ru}^{\mathrm{II}} / \mathrm{Ru}^{\mathrm{III}}$ couples, in $\mathbf{4}$ and $\mathbf{5}$, persuaded us to try to isolate the corresponding ruthenium(III) compounds in their pure states. Accordingly, attempts were made to oxidize them both chemically and electrochemically.

(28) Krejčík, M.; Zálišs, S.; Klíma, J.; Sýkora, D.; Matheis, W.; Klein, A.; Kaim, W. Inorg. Chem. 1993, 32, 3362.

(29) Ghosh, B. K.; Chakravorty, A. Coord. Chem. Rev. 1989, 95, 239.
Unfortunately, the oxidized complexes were not stable enough and revert to the parent bivalent complexes. However, we were successful at generating two representatives of the cationic complexes, viz. $[\mathbf{4 a}]^{+}$and $[\mathbf{5 a}]^{+}$, in solution by the controlled potential bulk electrolysis of $\mathbf{4 a}$ and $\mathbf{5 a}$. Well-resolved rhombic spectra of the above ruthenium complexes $[\mathbf{4 a}]^{+}$and $[\mathbf{5 a}]^{+}$were obtained in frozen $(77 \mathrm{~K})$ dichloromethane-toluene solution. The details are given in the Experimental Section.

The EPR data are collected in Table 4, and the representative spectra are shown in Figure 8. The observed rhombicity of the EPR spectra in the present cases is understandable in terms of the gross molecular symmetry of these complexes, containing three nonequivalent axes. ${ }^{30}$ The rhombic distortion can be thought of as a combination of axial distortion $(\Delta$, which splits $\mathrm{t}_{2}$ into a and e) and rhombic distortion $(V$, which splits e). Spin-orbit coupling causes further changes in the energy gaps. Thus, two electronic transitions of transition energies $\Delta E_{1}$ and $\Delta E_{2}\left(\Delta E_{1}<\Delta E_{2}\right)$ are, in principle, probable within these three levels. All these energy parameters for the above low spin ruthenium(III) complexes have been computed ${ }^{31}$ using the observed $g$-values. The axial distortion is much stronger than the rhombic one (Table 4). The analyses of the EPR spectral data thus indicate that both $[\mathbf{4 a}]^{+}$and $[\mathbf{5 a}]^{+}$are significantly distorted from ideal octahedral arrangements, which indeed is in agreement with the observed structures of the parent bivalent complexes.

The $\Delta E_{1}$ and $\Delta E_{2}$ transitions have been observed in the expected near-IR region and visible region, respectively. In view of approximations of the theory, the agreement between the calculated and observed transition energies is satisfactory.

\section{Conclusion}

Some examples of fascinating metal-promoted transformations, viz. amination and deamination at the pendant phenyl ring of coordinated 2-(phenylazo)pyridine, have been followed by the careful design of chemical reactions. The multiple products, from each of the reactions, have been purified and completely characterized. Electronic as well as kinetic reasons for the formation of the mixed ligand ruthenium complex $\left[\mathrm{RuCl}\left(\mathrm{HL}^{1}\right)\left(\mathrm{L}^{1}\right)\right](4)$ as against the bis chelate, $\left[\mathrm{Rh}\left(\mathrm{L}^{1}\right)_{2}\right] \mathrm{Cl}(\mathbf{2})$ have been noted. The deaminated products, particularly in the cases of rhodium, are found to be useful for the study of amination reactions. Regioselectivity of the amination reaction has been proven. The complexes thus formed show rich spectral as well as redox properties, which have been thoroughly investigated. Most notable is the appearance of intense intraligand chargetransfer transitions in the low-energy part of the visible region. The aminated organic ligands, in general, have both donor and acceptor chromophores, which are separated by the conjugated spacers. The complexes of these are under active scrutiny and might be useful in the development ${ }^{32}$ of nonlinear optically active materials.

(30) Reiger, P. H. Coord. Chem. Rev. 1994, 135/136, 203.

(31) Bhattacharya, S.; Chakravorty, A. Proc. Indian Acad. Sci., Chem. Sci. 1985, 95, 159 and references therein. 
Table 4. Electronic Spectra and EPR Data of the Cationic Compounds $[\mathbf{4 a}]^{+}$and $[\mathbf{5 a}]^{+}$

\begin{tabular}{|c|c|c|c|c|c|c|c|c|}
\hline \multirow[b]{2}{*}{ compd } & \multirow[b]{2}{*}{ electronic spectra ${ }^{a} \lambda_{\max }, \mathrm{cm}^{-1}$} & \multicolumn{7}{|c|}{ EPR $g$ values ${ }^{c}$ and derived energy params, ${ }^{d} \mathrm{~cm}^{-1}$} \\
\hline & & $g_{1}$ & $g_{2}$ & $g_{3}$ & $\Delta$ & $V$ & $\Delta E_{1}$ & $\Delta E_{2}$ \\
\hline$[\mathbf{4 a}]^{+}$ & $7930,11900,15430,^{b} 19530,27320,35460$ & 2.1437 & 2.0792 & 1.9699 & 10330 & 4800 & 7970 & 12850 \\
\hline$[5 \mathbf{a}]^{+}$ & $8200,11620,19450,27620,32470^{b}$ & 2.1367 & 2.0726 & 1.9729 & 10950 & 5430 & 8280 & 13780 \\
\hline
\end{tabular}
( $\lambda$ ) for low-spin ruthenium(II) as equal to $1000 \mathrm{~cm}^{-1}$.
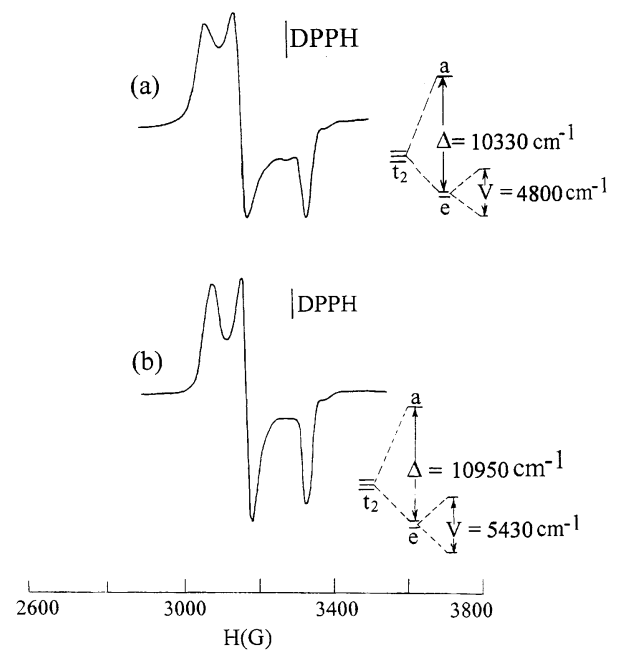

Figure 8. EPR spectra of (a) 4a and (b) 5a in 1:1 dichloromethanetoluene solution at $77 \mathrm{~K}$, also showing computed splittings of $\mathrm{t}_{2}$ orbitals. $\mathrm{DPPH}=$ diphenylpicrylhydrazyl.

\section{Experimental Section}

Materials. The starting metal salts $\mathrm{RhCl}_{3} \cdot 3 \mathrm{H}_{2} \mathrm{O}$ and $\mathrm{RuCl}_{3} \cdot 3 \mathrm{H}_{2} \mathrm{O}$ were digested thrice with concentrated $\mathrm{HCl}$ before use. The ligand $\mathrm{HL}^{1}$ and $\left[\mathrm{RhCl}_{2}(\text { pap })_{2}\right] \mathrm{ClO}_{4}$ were prepared following the reported $^{13,24}$ procedure. Solvents and chemicals used for the syntheses were of analytical grade.

Physical Measurements. Microanalytical data $(\mathrm{C}, \mathrm{H}, \mathrm{N})$ were collected from a Perkin-Elmer 240C elemental analyzer. A PerkinElmer 783 spectrophotometer was used for the measurement of IR spectral data. The ${ }^{1} \mathrm{H}$ NMR spectral data were recorded with a Bruker Avance 300 spectrophotometer using $\mathrm{SiMe}_{4}$ as an internal standard. Electrochemical measurements were performed at $298 \mathrm{~K}$ under a dry nitrogen atmosphere on a PC-controlled PAR Model 273A electrochemistry system. A platinum disk, a platinum wire auxiliary electrode, and an aqueous saturated calomel reference electrode (SCE) were used in a three-electrode configuration. The $E_{1 / 2}$ for the ferrocenium-ferrocene couple under our experimental condition was $0.39 \mathrm{~V}$. Electronic spectral data were recorded on a JASCO V-570 spectrophotometer. EPR spectral measurements were done on a Varian Model 109C E-line X-band spectrometer fitted with a quartz Dewar for measurement at $77 \mathrm{~K}$, and all spectral data were calibrated against the spectrum of DPPH.

Reactions of $\mathrm{RhCl}_{3} \cdot \mathbf{3 H}_{\mathbf{2}} \mathrm{O}$ with $\mathbf{H L}^{\mathbf{1}}$. The reactions of $\mathrm{RhCl}_{3}$. $3 \mathrm{H}_{2} \mathrm{O}$ with different substituted ligands $\left(\mathrm{HL}^{1 \mathrm{a}-} \mathrm{HL}^{1 \mathrm{c}}\right)$ were performed similarly to synthesize the compounds $\left[\mathrm{Rh}\left(\mathrm{L}^{1}\right)_{2}\right] \mathrm{Cl} 2$ and $\left[\mathrm{RhCl}(\operatorname{pap})\left(\mathrm{L}^{1}\right)\right] \mathrm{Cl} 3$, where $\left[\mathrm{L}^{1}\right]^{-}$is the conjugate base of $\mathrm{HL}^{1}$. A detail of a representative reaction with $\mathrm{HL}^{1 \mathrm{a}}$ is elaborated below.

Isolation of $\left[\mathrm{Rh}\left(\mathrm{L}^{1 \mathrm{a}}\right)_{2}\right] \mathrm{Cl}$ (2a) and $\left[\mathrm{RhCl}(\mathrm{pap})\left(\mathrm{L}^{1 \mathrm{a}}\right)\right] \mathrm{Cl}(3 \mathrm{a})$. To a reddish brown mixture of $\mathrm{RhCl}_{3} \cdot 3 \mathrm{H}_{2} \mathrm{O}(0.23 \mathrm{~g}, 0.88 \mathrm{mmol})$

(32) (a) Lacroix, P. G. Eur. J. Inorg. Chem. 2001, 339. (b) Bozec, H. L.; Remouazd, T. Eur. J. Inorg. Chem. 2000, 229. (c) Dhenaut, C.; Ledoux, I.; Samuel, I. D. W.; Zyss, J.; Bourgault, M.; Bozec, H. L. Nature 1995, 374, 339. (d) Zyss, J.; Ledoux, I. Chem. Rev. 1994, 94 , 77. and $\mathrm{HL}^{\text {1a }}(0.48 \mathrm{~g}, 1.76 \mathrm{mmol})$ in $60 \mathrm{~mL}$ of methanol, 2 drops of $\mathrm{NEt}_{3}$ was added. The mixture was refluxed on a steam bath. The color of the solution gradually turned green in $1 / 2 \mathrm{~h}$. The reaction was continued for $4 \mathrm{~h}$ for completion. The resultant solution was cooled and filtered. On evaporation of the green filtrate a dark mass was obtained, which was then loaded on a preparative silica gel TLC plate for separation. The solvent mixture chloroformacetonitrile (2:1) was used as the eluent. Two green bands $2 \mathbf{a}$ and 3a were separated. A dark greenish brown band was observed at the spot, which remained uneluted even with acetonitrile. The isolated green compounds were finally recrystallized from dichloromethane-hexane solvent mixture.

2a. Yield: 0.21 g, $35 \%$. Anal. Calcd for $\mathrm{C}_{34} \mathrm{H}_{26} \mathrm{~N}_{8} \mathrm{ClRh}$ : C, 59.62; H, 3.83; N, 16.36. Found: C, 59.57; H, 3.61; N, 16.25. MS: $m / z 649[\mathrm{M}-\mathrm{Cl}]^{+}$.

3a. Yield: 0.16 g, 29\%. Anal. Calcd for $\mathrm{C}_{28} \mathrm{H}_{22} \mathrm{~N}_{7} \mathrm{Cl}_{2} \mathrm{Rh}$ : C, 53.35; H, 3.52; N, 15.55. Found: C, 53.53; H, 3.72; N, 15.61. MS: $m / z 594[\mathrm{M}-\mathrm{Cl}]^{+}$.

The yields and the analytical data of $\mathbf{2 b}, \mathbf{3 b}$ and $\mathbf{2 c}, \mathbf{3} \mathbf{c}$ are given below:

2b. Yield: $35 \%$. Anal. Calcd for $\mathrm{C}_{36} \mathrm{H}_{30} \mathrm{~N}_{8} \mathrm{ClRh}$ : C, 60.64; $\mathrm{H}$, 4.24; N, 15.71. Found: C, 60.51; H, 4.30; N, 15.55.

3b. Yield: $30 \%$. Anal. Calcd for $\mathrm{C}_{29} \mathrm{H}_{24} \mathrm{~N}_{7} \mathrm{Cl}_{2} \mathrm{Rh}$ : C, 54.05; $\mathrm{H}$, 3.75; N, 15.22. Found: C, 54.15; H, 3.80; N, 15.32 .

2c. Yield: $32 \%$. Anal. Calcd for $\mathrm{C}_{32} \mathrm{H}_{24} \mathrm{~N}_{10} \mathrm{ClRh}$ : C, 55.95; $\mathrm{H}$, 3.52; N, 20.39. Found: C, 55.84; H, 3.48; N, 20.31.

3c. Yield: $28 \%$. Anal. Calcd for $\mathrm{C}_{27} \mathrm{H}_{21} \mathrm{~N}_{8} \mathrm{Cl}_{2} \mathrm{Rh}$ : C, 51.37; $\mathrm{H}$, 3.35; N, 17.75. Found: C, 51.32; H, 3.19; N, 17.64.

Reactions of $\operatorname{RuCl}_{3} \cdot \mathbf{3 H}_{2} \mathrm{O}$ with $\mathrm{HL}^{1}$. The reactions of $\mathrm{RuCl}_{3}$. $3 \mathrm{H}_{2} \mathrm{O}$ with $\mathrm{HL}^{1 \mathrm{a}}$ and $\mathrm{HL}^{1 \mathrm{~b}}$ were performed by following a similar procedure. A detail of a representative is elaborated below.

Isolation of $\left[\operatorname{RuCl}\left(\mathrm{HL}^{1 \mathrm{a}}\right)\left(\mathrm{L}^{1 \mathrm{a}}\right)\right](4 \mathrm{a})$ and $\left[\operatorname{RuCl}(\operatorname{pap})\left(\mathrm{L}^{1 \mathrm{a}}\right)\right](5 \mathrm{a})$. To a reddish mixture of $\mathrm{RuCl}_{3} \cdot 3 \mathrm{H}_{2} \mathrm{O}(0.23 \mathrm{~g}, 0.89 \mathrm{mmol})$ and $\mathrm{HL}^{1 \mathrm{a}}$ $(0.49 \mathrm{~g}, 1.78 \mathrm{mmol})$ in $60 \mathrm{~mL}$ of methanol, 2 drops of $\mathrm{NEt}_{3}$ was added. The mixture was refluxed on a steam bath for $5 \mathrm{~h}$. The initial reddish color changed to dark brown during this period. The resultant solution was cooled and filtered. On evaporation of the filtrate a dark crude mass was obtained. It was washed thoroughly with diethyl ether. The crude mass was recrystallized several times from dichloromethane-hexane mixture. Then it was subjected to chromatography on a preparative silica gel TLC plate using a benzene-chloroform mixture (3:2) as the eluent. Two brown bands 4a and 5a were separated gradually after allowing sufficient time. The other byproducts, the three isomers of $\left[\mathrm{RuCl}_{2}(\mathrm{pap})_{2}\right]$, formed in this reaction were also isolated as distinct bands using chloroform as the eluent. Some minor brownish violet bands were also observed on the TLC plate, which could not be isolated in pure form.

4a. Yield: $0.07 \mathrm{~g}, 11 \%$. Anal. Calcd for $\mathrm{C}_{34} \mathrm{H}_{27} \mathrm{~N}_{8} \mathrm{ClRu}$ : C, 59.69; H, 3.98; N, 16.38. Found: C, 59.48; H, 4.12; N, 16.23.

5a. Yield: 0.12 g, $23 \%$. Anal. Calcd for $\mathrm{C}_{28} \mathrm{H}_{22} \mathrm{~N}_{7} \mathrm{ClRu}$ : C, 56.71; H, 3.74; N, 16.53. Found: C, 56.53; H, 3.90; N, 16.39 .

The yields and analytical data of $\mathbf{4 b}$ and $\mathbf{5 b}$ are as follows:

4b. Yield: $12 \%$. Anal. Calcd for $\mathrm{C}_{36} \mathrm{H}_{31} \mathrm{~N}_{8} \mathrm{ClRu}$ : C, 60.71; $\mathrm{H}$, 4.39; N, 15.73. Found: C, 60.47; H, 4.19; N, 15.45 . 
Das et al.

Table 5. Crystal Data for Compound 2c, 3a, 4a, 5a and 6d

\begin{tabular}{|c|c|c|c|c|c|}
\hline & $2 \mathrm{c} \cdot 4 \mathrm{H}_{2} \mathrm{O}$ & $\mathbf{3 a} \cdot 4 \mathrm{H}_{2} \mathrm{O}$ & $4 a$ & $5 a$ & 6d \\
\hline empirical formula & $\mathrm{C}_{32} \mathrm{H}_{32} \mathrm{ClN}_{10} \mathrm{O}_{4} \mathrm{Rh}$ & $\mathrm{C}_{28} \mathrm{H}_{30} \mathrm{Cl}_{2} \mathrm{~N}_{7} \mathrm{O}_{4} \mathrm{Rh}$ & $\mathrm{C}_{34} \mathrm{H}_{27} \mathrm{ClN}{ }_{8} \mathrm{Ru}$ & $\mathrm{C}_{28} \mathrm{H}_{22} \mathrm{ClN}_{7} \mathrm{Ru}$ & $\mathrm{C}_{36} \mathrm{H}_{31} \mathrm{ClF}_{6} \mathrm{~N}_{8} \mathrm{PRh}$ \\
\hline formula weight & 759.04 & 702.40 & 684.16 & 593.05 & 859.02 \\
\hline temp $[\mathrm{K}]$ & $293(2)$ & $293(2)$ & $295(2)$ & $293(2)$ & $150(2)$ \\
\hline cryst syst & monoclinic & monoclinic & monoclinic & monoclinic & triclinic \\
\hline space group & $P 2(1) / n$ & $P 2(1) / c$ & $P 2(1) / n$ & $P 2(1) / n$ & $P \overline{1}$ \\
\hline$a[\AA]$ & $11.8962(7)$ & $19.7142(11)$ & $10.998(2)$ & $13.481(7)$ & $8.9645(8)$ \\
\hline$b[\AA]$ & $22.2032(14)$ & $7.8744(4)$ & 20.067(4) & 14.377(9) & $12.4699(12)$ \\
\hline$c[\AA]$ & $13.4009(8)$ & 20.4434(11) & $14.530(3)$ & $13.543(7)$ & $17.0283(17)$ \\
\hline$\alpha[\mathrm{deg}]$ & 90 & 90 & 90 & 90 & $107.483(2)$ \\
\hline$\beta$ [deg] & $105.7390(10)$ & $101.5580(10)$ & $110.26(2)$ & $91.83(4)$ & $104.519(2)$ \\
\hline$\gamma[\mathrm{deg}]$ & 90 & 90 & 90 & 90 & $92.834(2)$ \\
\hline$Z$ & 4 & 4 & 4 & 4 & 2 \\
\hline$D_{\text {calcd }}\left[\mathrm{mg} / \mathrm{m}^{3}\right]$ & 1.480 & 1.501 & 1.511 & 1.502 & 1.638 \\
\hline cryst dimen $\left[\mathrm{mm}^{3}\right]$ & $0.30 \times 0.12 \times 0.08$ & $0.24 \times 0.23 \times 0.21$ & $0.60 \times 0.50 \times 0.40$ & $0.50 \times 0.40 \times 0.40$ & $0.34 \times 0.21 \times 0.07$ \\
\hline$\theta$ range for data collection $[\mathrm{deg}]$ & $1.83-27.51$ & $2.03-27.53$ & $1.81-25$ & $2.07-24.01$ & $1.31-27.52$ \\
\hline GOF & 0.895 & 0.864 & 1.064 & 1.047 & 0.819 \\
\hline reflns collected & 21424 & 19165 & 5295 & 4470 & 11255 \\
\hline unique reflns & 7746 & 7097 & 5295 & 4027 & 7761 \\
\hline \multirow[t]{2}{*}{ final $R$ indices $[I>2 \sigma(I)]$} & $\mathrm{R} 1=0.0485$ & $\mathrm{R} 1=0.0378$ & $\mathrm{R} 1=0.0252$ & $\mathrm{R} 1=0.0512$ & $\mathrm{R} 1=0.0506$ \\
\hline & $w \mathrm{R} 2=0.1343$ & $w R 2=0.0895$ & $w \mathrm{R} 2=0.0645$ & $w \mathrm{R} 2=0.1151$ & $w \mathrm{R} 2=0.1071$ \\
\hline
\end{tabular}

5b. Yield: 22\%. Anal. Calcd for $\mathrm{C}_{29} \mathrm{H}_{24} \mathrm{~N}_{7} \mathrm{ClRu}$ : C, 57.38; $\mathrm{H}$, 3.98; N, 16.15. Found: C, 57.17; H, 4.11; N, 16.01.

Amination Reactions. Two different routes of amination reactions on coordinated pap ligand have been explored. In the first route we have described the amination reaction of coordinated pap in $\left[\mathrm{RhCl}(\mathrm{pap})\left(\mathrm{L}^{1}\right)\right] \mathrm{Cl}(\mathbf{3})$. The second method involves the reaction of $\left[\mathrm{RhCl}_{2}(\text { pap })_{2}\right] \mathrm{ClO}_{4}$ (1) with different $\mathrm{ArNH}_{2}$ compounds. The products, obtained from the two routes, are identical but the yields are different.

Method I. [3] $]^{+} \rightarrow[6]^{+}$, a Representative Example: Synthesis of $\left[\mathbf{R h C l}\left(\mathbf{H L}^{2 \mathbf{a}}\right)\left(\mathbf{L}^{\mathbf{1 a}}\right)\right]^{+},[\mathbf{6 a}]^{+}$. A sample of $\left[\mathrm{RhCl}(\mathrm{pap})\left(\mathrm{L}^{1 \mathrm{a}}\right)\right] \mathrm{Cl}(\mathbf{3 a})$ $(0.20 \mathrm{~g}, 0.32 \mathrm{mmol})$ was mixed with $0.5 \mathrm{~mL}$ of aniline, and the mixture was heated on a steam bath. The green mixture turned blue within $15 \mathrm{~min}$. The reaction was continued for $3 \mathrm{~h}$ for the completion of the reaction. The mixture was then cooled and thoroughly washed with diethyl ether. A blue compound was purified on a preparative TLC plate (silica gel) using chloroformacetonitrile mixture (3:1) as the eluent. Finally the compound, as its chloride salt, was recrystallized from dichloromethane-hexane solvent mixture. Yield: $0.18 \mathrm{~g}, 78 \%$. Anal. Calcd for $\mathrm{C}_{34} \mathrm{H}_{27} \mathrm{~N}_{8-}$ $\mathrm{Cl}_{2} \mathrm{Rh}$ : C, 56.60; H, 3.77; N, 15.53. Found: C, 56.47; H, 3.63; N, 15.42. MS: $m / z 685[\mathrm{M}-\mathrm{Cl}]^{+}$.

The yields and analytical data of $\mathbf{6 b}, \mathbf{6 c}$, and $\mathbf{6 d}$ are given below.

6b. Yield: $78 \%$. Anal. Calcd for $\mathrm{C}_{35} \mathrm{H}_{29} \mathrm{~N}_{8} \mathrm{Cl}_{2} \mathrm{Rh}$ : C, 57.16; $\mathrm{H}$, 3.97; N, 15.23. Found: C, 57.41; H, 4.12; N, 15.39. MS: $m / z 699$ $[\mathrm{M}-\mathrm{Cl}]^{+}$.

6c. Yield: $75 \%$. Anal. Calcd for $\mathrm{C}_{35} \mathrm{H}_{29} \mathrm{~N}_{8} \mathrm{Cl}_{2} \mathrm{ORh}$ : C, 55.94; H, 3.89; N, 14.91. Found: C, 55.85; H, 3.80; N, 14.98.

6d. Yield: $80 \%$. Anal. Calcd for $\mathrm{C}_{36} \mathrm{H}_{31} \mathrm{~N}_{8} \mathrm{Cl}_{2} \mathrm{Rh}$ : C, 57.69; $\mathrm{H}$, 4.17; N, 14.95. Found: C, 57.52; H, 4.01; N, 14.85 .

Method II. $[1]^{+} \rightarrow[6]^{+}$, a Representative Example: Synthesis of $\left[\mathbf{R h C l}\left(\mathbf{H L}^{2 \mathbf{a}}\right)\left(\mathbf{L}^{\mathbf{1 a}}\right)\right]^{+},[\mathbf{6 a}]^{+}$. A mixture of $\left[\mathrm{RhCl}_{2}(\text { pap })_{2}\right] \mathrm{ClO}_{4}$ $(0.20 \mathrm{~g}, 0.31 \mathrm{mmol})$ and aniline $(0.5 \mathrm{~mL})$ was heated on a steam bath for $2 \mathrm{~h}$. The cooled blue mixture was thoroughly washed with diethyl ether. The crude mass was purified on a preparative TLC plate (silica gel) using chloroform-acetonitrile solvent mixture (3: 1) as the eluent. Recrystallization of the product from a dichloromethane-hexane solvent mixture yielded dark blue cationic compound 6a as its perchlorate salt. Yield: $0.13 \mathrm{~g}, 55 \%$. Anal. Calcd for $\mathrm{C}_{34} \mathrm{H}_{27} \mathrm{~N}_{8} \mathrm{Cl}_{2} \mathrm{O}_{4} \mathrm{Rh}$ : C, 51.99; H, 3.46; N, 14.26. Found: C, 51.73; H, 3.33; N, 14.02. MS: $m / z, 685\left[\mathrm{M}-\mathrm{ClO}_{4}\right]^{+}$.

The cationic compound $[\mathbf{6 a}]^{+}$obtained following method II is identical to that obtained from method I. We, however, note that the two ligands in the product 6 (method II) carries identical substitution, R, depending on the starting $\mathrm{ArNH}_{2}$. The starting rhodium complex $\mathbf{3}$ is, in fact, the intermediate for the reaction $\mathbf{1}$ $\rightarrow \mathbf{6}$ (vide supra). Hence the two ligands in the products, obtained from 3, may not necessarily bear identical substitutions.

Electrochemical Generation of $[4 \mathbf{a}]^{+}$and $[\mathbf{5 a}]^{+}$. The complexes $[\mathbf{4 a}]^{+}$and $[\mathbf{5 a}]^{+}$were generated in solution by constant potential coulometric oxidation of solutions of $\mathbf{4 a}$ and $\mathbf{5 a}$, respectively. A detail of a representative example $\left([\mathbf{4} \mathbf{a}]^{+}\right)$is noted below.

A solution of $9.0 \mathrm{mg}$ of $\mathbf{4 a}$ in $30 \mathrm{~mL}$ of dichloromethane solvent containing $35 \mathrm{mg}$ of tetrabutylammoniumperchlorate was oxidized coulometrically. The oxidation was performed at $0.65 \mathrm{~V} ; n=1.22$ / $1.27=0.96, n=Q / Q^{\prime}$, where $Q$ is the coulomb count found after exhaustive electrolysis and $Q^{\prime}$ is the calculated coulomb count for one-electron transfer. A part of the electrogenerated solution $(5 \mathrm{~mL})$ of $[\mathbf{4 a}]^{+}$was mixed with an equal volume of toluene, and the mixture was quickly frozen at $77 \mathrm{~K}$ and then used for an EPR measurement. The oxidized complex $[\mathbf{4 a}]^{+}$was not stable at room temperature. It underwent reduction to produce $\mathbf{4 a}$ almost quantitatively. To date, we were not successful in isolating the trivalent ruthenium compound $[\mathbf{4 a}]^{+}$in its pure state.

The trivalent complex $[\mathbf{5 a}]^{+}$was generated in solution similarly as described above.

Crystallography. Crystallographic data for the compounds $\mathbf{2 c}$, 3a, 4a, 5a, and $\mathbf{6 d}$ are collected in Table 5. The suitable X-ray crystals of $\mathbf{2 c}$ and $\mathbf{3 a}$ were obtained by slow diffusion of a dichloromethane solution of chloride salt of $\mathbf{2} \mathbf{c}$ and $\mathbf{3 a}$ into hexane. The X-ray crystals of $\mathbf{6} \mathbf{d}$ were obtained by slow diffusion of a dichloromethane solution of hexaflourophosphate salt of $\mathbf{6 d}$ into hexane. Intensity data of all these three compounds (2c, 3a, and 6d) were collected on a Bruker SMART diffractometer, equipped with graphite monochromated Mo $\mathrm{K} \alpha$ radiation, $\lambda=0.71073 \AA$. These were corrected for Lorentz polarization effects. All three structures were solved by employing SHELXS-9733 package of programs and refined by full matrix least squares based on $F^{2}$ (SHELXL-97). ${ }^{34}$ The X-ray quality crystals of $\mathbf{4 a}$ were obtained by the slow diffusion of a dichloromethane solution of $\mathbf{4 a}$ into hexane. Intensity data were collected on a NONIUS CAD4 diffractometer, equipped with graphite monochromated Mo $\mathrm{K} \alpha, \lambda$

(33) Sheldrick, G. M. Acta Crystallogr., Sect. A 1990, 46, 467.

(34) Sheldrick, G. M. SHELXL97, Program for the Refinement of Crystal Structures; University of Göttingen: Göttingen, Germany, 1997. 
$=0.71073 \AA$. The data were corrected for Lorentz polarization effects. The X-ray quality crystals of $\mathbf{5 a}$ were grown by slow diffusion of a toluene solution of 5a into hexane. Intensity data were collected on a Sieman $\mathrm{R} 3 \mathrm{~m} / \mathrm{V}$ diffractometer with graphite monochromated Mo K $\alpha$ radiation, $\lambda=0.71073 \AA$. All the data were corrected for Lorentz polarization effects. The structures of compounds 4a and 5a were solved by using the SHELXS-86 package ${ }^{35}$ of programs and refined by full matrix least squares based on $F^{2}$ (SHELXL-93). ${ }^{36}$ All the hydrogen atoms were added in calculated positions.

(35) Sheldrick, G. M. SHELXS86, Program for the Solution of Crystal Structures; University of Göttingen: Göttingen, Germany, 1990.

(36) Sheldrick, G. M. SHELXL93, Program for the Refinement of Crystal Structures; University of Göttingen: Göttingen, Germany, 1993.
Acknowledgment. Financial support received from the Department of Science and Technology and The Council of Scientific and Industrial Research (New Delhi) is gratefully acknowledged. We are thankful to Prof. Animesh Chakravorty and Dr. Samaresh Bhattacharya for help. Thanks are due to RSIC, Lucknow, for providing mass spectra.

Supporting Information Available: X-ray crystallographic details in CIF format of the five compounds $\mathbf{2 c}, \mathbf{3 a}, \mathbf{4 a}, \mathbf{5 a}$, and 6d; molecular orbital diagram of 3a: (a) LUMO, (b) HOMO, and (c) HOMO -1 . These materials are available free of charge via the Internet at http://pubs.acs.org.

IC020421C 